\title{
Article \\ Designing of Machine Backups in Reconfigurable Manufacturing Systems
}

\author{
Vladimír Vavrík (D), Miroslav Fusko*(D), Monika Bučková (D), Martin Gašo (D), Beáta Furmannová (D) \\ and Katarína Štaffenová
}

check for updates

Citation: Vavrík, V.; Fusko, M.; Bučková, M.; Gašo, M.; Furmannová, B.; Štaffenová, K. Designing of Machine Backups in Reconfigurable Manufacturing Systems. Appl. Sci. 2022, 12, 2338. https://doi.org/ 10.3390/app12052338

Academic Editor: Antonella Petrillo

Received: 1 February 2022

Accepted: 22 February 2022

Published: 23 February 2022

Publisher's Note: MDPI stays neutral with regard to jurisdictional claims in published maps and institutional affiliations.

Copyright: (c) 2022 by the authors. Licensee MDPI, Basel, Switzerland. This article is an open access article distributed under the terms and conditions of the Creative Commons Attribution (CC BY) license (https:// creativecommons.org/licenses/by/ $4.0 /)$.
Department of Industrial Engineering, University of Žilina, 01026 Zilina, Slovakia; vladimir.vavrik@fstroj.uniza.sk (V.V.); monika.buckova@fstroj.uniza.sk (M.B.); martin.gaso@fstroj.uniza.sk (M.G.); beata.furmannova@fstroj.uniza.sk (B.F.); katarina.staffenova@fstroj.uniza.sk (K.Š.)

* Correspondence: miroslav.fusko@fstroj.uniza.sk

\begin{abstract}
The article presents the results of machine backup designing in reconfigurable industrial processes. The development of manufacturing systems is moving towards intelligent, automated, autonomous, and reconfigurable manufacturing systems. Factories that want to ensure long-term sustainable and competitive manufacturing processes must be designing their processes to respond flexibly to changing changes in customer requirements. The article's introduction characterizes concepts such as cold backup and warm backup machines and indicators relationship as the time between faults and repairs. The materials and methods describes prerequisites as the creation of the product family creation and resource availability with many formulas, simulation models, and its verification for the creation of the family products in the results of this article. The results describes the results from the calculations of the backups and family products of their use in reconfigurable manufacturing systems. The developed methodology for line design uses the principles of reconfiguration in designing configurations regarding advanced approaches in factories. A significant milestone will be the rapid integration of disruptive technologies and approaches into manufacturing systems. The complexity of future manufacturing systems in the Factories of the Future will only be possible with new innovative factory technologies using the digital twin.
\end{abstract}

Keywords: machine backups; reconfigurability; modular manufacturing lines; competent islands; Factories of the Future; simulation; advanced industrial engineering

\section{Introduction}

The European Union has defined sustainable manufacturing as its primary strategic goal for the coming years. This manufacturing must create products with high added value for the customer. Forecasters have identified digitization and digital technologies as the main drivers of productivity growth and competitiveness at the beginning of the 21st century. Future needs in industrial technologies result from customers' changing requirements, needs, and possibilities. New generations of manufacturing systems correspond to this. The condition for success is the rapid, practical use of technological research results, i.e., the commercialization of technologies [1]. The closure of the cycle will support this: basic research-applied research-development-prototype-product-profit from sales-new investment in research.

The latest developments in industrial technology are referred to as key enabling technologies (KETs). These technologies are knowledge-intensive and capital-intensive, combined with cutting-edge research and development. KETs are the driving force behind rapid innovation cycles, require highly qualified researchers and experts, are multidisciplinary and trans-sectoral, condition and enable product, process, and service innovation. These technologies form the core of innovation in the most advanced products. Factories of the Future (FoF) must have adjustability properties, i.e., reconfigurability. Future businesses must have reconfigurability features $[2,3]$. 
The factory management systems of the future will be developed (emulated) in a digital factory environment using digital models. Verified management software is easily transferred to a real factory. Therefore, the digital model of the factory must integrate the following entities: buildings, people, technology, transport, management, energy and energy system, maintenance. The optimization focus will be transferred to the technological preparation of manufacturing, using simulation and emulation technologies. New business models will also be an integral part of future factory research [4-6].

Currently, the globalization of the market is intensifying, which creates significant fluctuations in demand, and therefore conventional manufacturing systems are no longer an appropriate solution to market problems. Reconfigurable manufacturing systems (RMS), could become a technological response to the market situation, which allows you to set the required manufacturing capacity depending on the market demand. The need to change the approach to product manufacturing must also change the design of manufacturing systems and their configurations. Therefore, the following study deals with a partial solution of the calculation of equipment backups of the implemented methodology for a modular, reconfigurable line, the purpose of which will be the dynamic creation of configurations for product families $[7,8]$.

When dealing with backups, it is necessary to define reliability indicators [9] (see Figure 1), which reveal different time expressions. The basic ones include MTBF-mean time between failures, MTTR - mean time to repair and MTTF-mean time to failure.

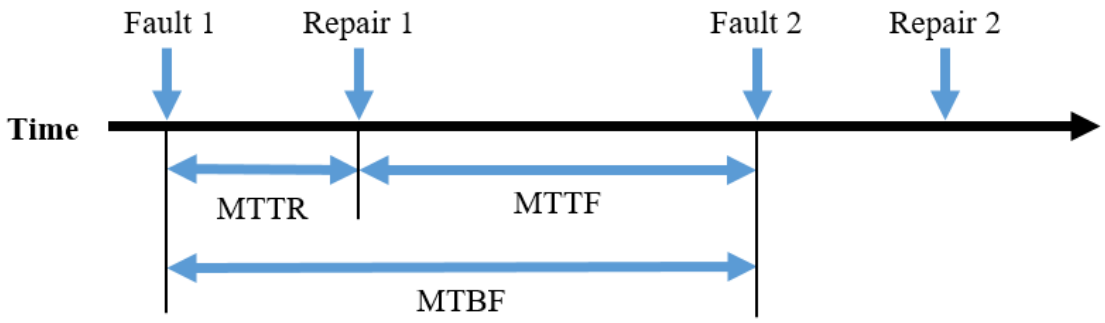

Figure 1. Indicators relationship.

A new challenge for research is intelligent solutions $[10,11]$ based on artificial intelligence methods and the growing trend of decision support systems and knowledge systems. New technologies used in factories include virtual reality, augmented reality, and virtual testing technologies. Future manufacturing systems will be characterized by the mass deployment of a new generation of comprehensive, knowledgeable robotic systems and systems for designing and digitizing manufacturing systems in all factory activities. Therefore, one of the priority topics must be industrial and service robotics. Minimizing the energy intensity of technological processes will become a critical factor in the future. In the future, optimization of energy consumption will not be possible without applying the most modern systems in electrical engineering, information technologies (IT), information and communication technologies (ICT), and new types of energy. These will be modern drives and devices for controlling the flow of various types of energy [12,13]. Professor Yoram Koren, in his article [14], defined the reconfigurable manufacturing systems (RMS) as a reconfigurable manufacturing system (RMS) is one designed for rapid adjustment of production capacity and functionality, in response to new circumstances, by rearrangement or change of its hardware and software components.

We performed possible solutions overview of designing machine backups in reconfigurable manufacturing systems in the three databases: Scopus, Web of Science (WoS), and Current Contents Connect (CCC). After analyzing and studying the selected documents, we concluded that there is no methodology for reconfigurable systems for cold and warm backup and for reconfigurable systems too. The following articles came closest to our problem.

In the article [15] the authors deal with Kubernetes as an open-source solution. In the article [16] the authors describe the difference between cold and warm backup and 
present an optimization model to reduce device downtime. In the article [17] the authors describe just a simple example. The article [18] presents a numerical methodology to model and evaluate reliability. In article [19], the authors describe the cold deposit as a planned activity. In article [20], the authors describe only cyber security and backup from the point of view of the software solution. According to the article [21], system reconfiguration ensures system operation and maintains system "ilities" (e.g., reliability, availability, maintainability, testability, and safety). Authors used MBSysRec method that involves configuration generation and a multicriteria decision-making method for configuration evaluation and selection to support system reconfiguration during operations. In article [22], authors describe the implementation of their proposed part family grouping method. In article [23], authors focused on the reconfiguration decision-making system with the data acquisition system based on IoT technology. Article [24] deals with the analysis and control of dynamic reconfiguration process of manufacturing systems from the perspective of discrete event systems. Article [25] provides a literature review and an analysis of the studies related to workforce reconfiguration strategies as a part of workforce planning for various production environments.

Based on a detailed analysis of selected articles, we did not find a connection with our solving area. The displayed articles describe cold and warm backup, but solve it in their unique solutions. Many articles describe warm and cold backup in software solutions. The innovativeness of the proposed methodology lies in the interconnection of several unrelated methods and the use of their potential in solving product planning and scheduling for a modular production line. An exciting solution includes, for example, the use of the LCS algorithm to find product similarities, which is given by the longest chain of joint product operations. Moreover, the new element includes a view of the system as a dynamically changing element and the proposal of a designing system that considers a change in production disposition over time according to market requirements and criteria defined by the factory. By implementing the proposed solution, the processes in the factories will respond flexibly to unexpected market fluctuations.

\section{Materials and Methods}

Designing reconfigurable manufacturing lines is a complex solution and consists of various modules (see Figure 2). Figure 2 shows the module Product family creation, in red, which is described in detail in the present article. The modules from Figure 2 were characterized in detail in the study: the design of manufacturing lines using the principle of reconfigurability [26]. Therefore, only a brief description of their function and purpose concerning the overall methodology is given. This study [26] deals with a general description of the proposed calculation model. Still, it does not detail the principles for calculating equipment advances for this methodology, nor the product family creation process and simulation. At the end of the article is the nomenclature of all variables used.

After defining specific parameters in the input data procedure module, the algorithm of the proposed methodology verifies the feasibility of the defined operations from the time and operational point of view (module capacity and operational availability). If the products meet the specified conditions, the validation of product manufacturability in time procedure is continued. This module defines the criterion of the minimum time required to produce each product. The sequence of assigning products to a product family is further defined using this data. The assignment sequence is defined by the Short Processing Time criteria and the Cluster analysis results. Subsequently, product families are created, and the required backup is calculated for each new product family. After defining the backup and the specific number of machines, the product family products are produced until the end of manufacturing one of the family products. This is followed by another iteration of creating a new product family, thus re-determining the number of machines and the required backups. 


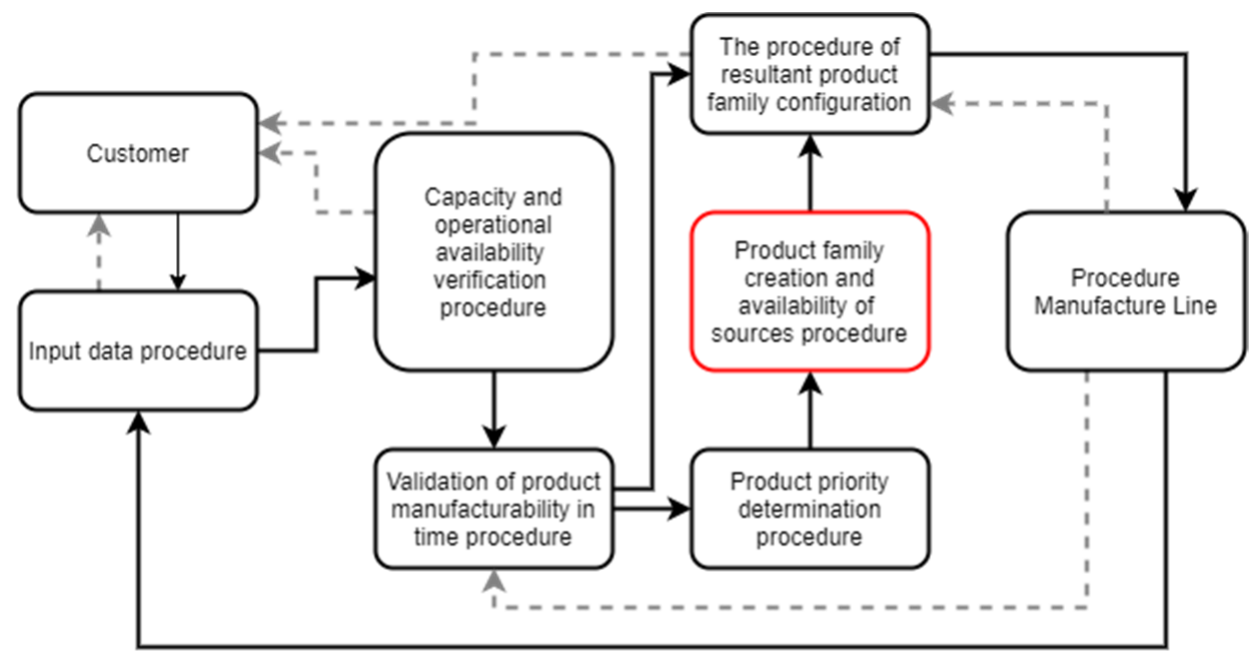

$\uparrow$

Information flow

Feedback

Figure 2. Modules of the designing reconfigurable manufacturing lines.

Professor Yoram Koren defined six core RMS characteristics [27]:

- Scalability (Design for capacity changes)-The capability of modifying production capacity by adding or removing resources and/or changing system components;

- Convertibility (Design for functionality changes)-The capability of transforming the functionality of existing systems and machines to fit new production requirements;

- Diagnosability (Design for easy diagnostics) - The capability of real-time monitoring the product quality, and rapidly diagnosing the root causes of product defects;

- Customization (Flexibility limited to part family) - System or machine flexibility around a part family, obtaining thereby customized flexibility within the part family;

- Modularity (Modular components) - The compartmentalization of operational functions into units that can be manipulated between alternative production schemes;

- Integrability (Interfaces for rapid integration)-The capability of integrating modules rapidly and precisely by hardware and software interfaces.

Our articles primary deals with fourth point-Customization. But in complex way, we must solve all six core characteristics. So, the article deals more with the product family creation module, which consists of three main parts. This module must prepare the necessary data and sources before the design solution (Section 3). The first part is the creation of a product family cluster $(\alpha)$ and determining the production volume for the defined operations of the production configuration. The second part is recalculating the required number of machines $\left(q_{\alpha}\right)$ for the proposed configuration and its subsequent verification utilizing simulation software. The third part specifies the required device backup for a verified configuration containing two or more products. The products are assigned sequentially depending on the proposed overall assignment sequence and the number of unassigned system devices. The last step of the third part is to check the configuration in the assignment submodule, which determines the number of assigned devices for the family products and sends the value of the number of assigned devices to the next decision module. In the following paragraphs, the areas of simulation creation for this methodology and the corresponding recalculation of backup creation will be specified in detail. The other parts of the product family creation module (tags (A) (B) and (C)) will be described without giving detailed recalculations concerning the overall scope of the solution.

In connection with the following steps (A) and (B), we compared several studies [28-31]. The differences between our approach and them are as follows: 
- The authors in these studies use similar principles to design a flexible system. Still, the solution of our study deals with several areas and addresses the issue more comprehensively;

- Although in the mentioned studies, the individual devices are assigned based on the similarity of the tooling, the groups created cannot be changed dynamically over time. What happens if a new product arrives and needs to be processed as a matter of priority or production needs to be transformed into the product currently required? The methodology developed by us deals with these issues, which are currently beginning to resonate significantly in the conditions in manufacturing companies (turbulent market during the corona period, lack of materials, etc., i.e., the impact on frequent changes in the product mix);

- The studies also lack the presence of a calculation of the necessary equipment for processing a particular product, and this is one of the supporting parts of our study. This part is also followed by a dynamic simulation model, which verifies the need for these devices. This verification is necessary because the static conversion model cannot verify the product wait states in the hopper/conveyor if the machine is busy. These conditions then significantly change the need for machinery to produce a product mix consisting of two or more types of products that have different machining times in the same type of operation (e.g., milling part $\mathrm{K} 1=5 \mathrm{~min}$. But milling part $\mathrm{K} 2=4 \mathrm{~min}$ );

- Another fundamental difference is the verification of similarity between products. Our study focuses on the LCS algorithm's longest common chain of products operations and not only on the very similarity of operations performed on devices. Only this similarity decides on the division of the product into a monastery through Monastery analysis.

(A) The first part of creating a product family consists of grouping similar products into a product family, and this operation can be considered the core of the proposed methodology. Products subject to mutual similarity in operation type (production technology) are grouped. The creation of a family is not only subject to the finding of joint operations between products, as it is necessary to determine the most extended sequence of the same operations (similarity of the production/assembly process). The determination of this sequence of operations on products is performed using the Longest Common Subsequence submodule (LCS). In this module (see Figure 3), the LCS algorithm finds and determines the specified sequence of operations of the product pair. In the case of an already formed cluster of two or more products, it creates a sequence between the product-formed cluster $\alpha$. Said mutual sequence of the same operations can subsequently be written as a matrix $L C S_{\alpha}$. When creating a cluster, several products or a previous cluster enters the joining process. However, their operations are generally defined by matrices $N A M E_{k n, \ldots, k m}$ for products and a matrix $N A M E_{\alpha}$ for clustering. The grouping of individual products consists of the following steps:

- Assessment of the first condition. This condition compares the operation of the incoming product $\left(o p a_{i o}\right)$ with the element matrix of the common elements $\left(l c s_{t o}\right)$. If the operations are the same, another condition follows.

- Assessment of the second condition. This condition compares the element matrix $\left(o p b_{i o}\right)$ with the element matrix of the common elements $\left(l c s_{d o}\right)$. If all three elements are identical, the operation is assigned to the new result matrix $N A M E_{\alpha}$, and the sum of the operating times $t a_{i o}$ and $t b_{j o}$ of these identical operations is necessary. However, if the element $o p a_{i o}$ does not match the element $l c s_{d o}$, it is necessary to verify the variable " $k$ " with the number of matrix elements marked as Sp $\alpha$. If the common elements are exhausted, operations are assigned only from the second matrix $O P B$. If not all common elements are assigned, the elements of OPA are assigned to the matrix $N A M E_{\alpha}$. The whole assignment cycle lasts unless the variable is equal to the value of the maximum number of operations $P O C P_{k n}$ from the selected products. 

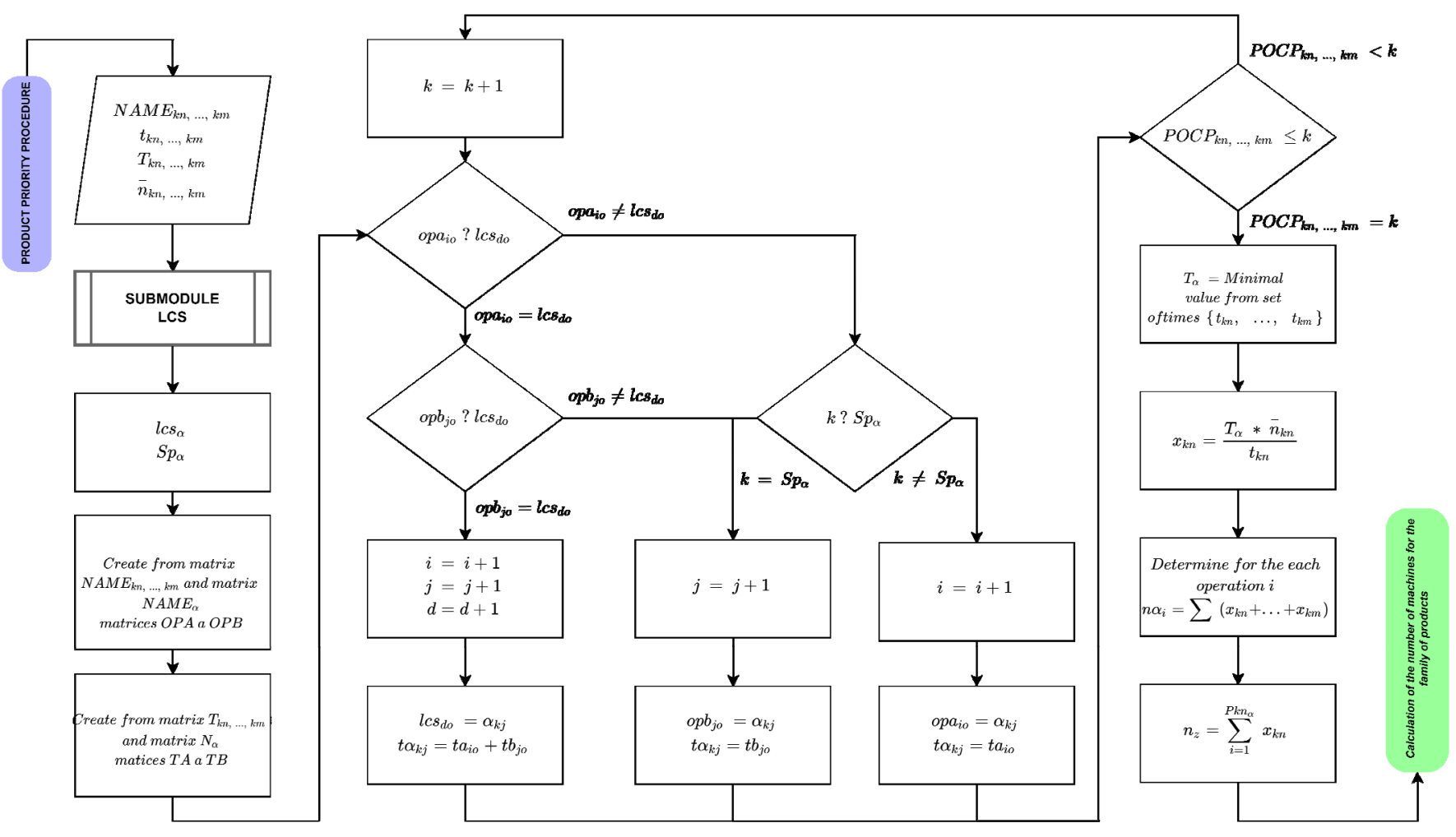

Figure 3. The first part of the module algorithm—The product family creation and resource availability.

The basic principle of creating a product family is based on the LCS algorithm; this algorithm determines the mutual similarity of products for Cluster analysis and defines the identical elements for merging products into a product family. If the product contains the same operations, they are classified at the same production stages as other products in the family. This process of merging products occurs at the end of the algorithm, and products are gradually assigned to the product family based on a predetermined order (this order is given by Cluster analysis).

The described point (A) in the article deals with merging products into a family. The Figure 4 has been elaborated for closer understanding. In the first column is the first product $\mathrm{K} 1$, which is selected in the product family (matrix OPA-first column). Together with the product $\mathrm{K} 8$ (matrix $O P B$-third column), this product evaluates the LCS algorithm and determines the common elements (matrix $\mathrm{LCS}_{\alpha}$ - second column). Subsequently, set procedures in VBA combine the necessary elements of operating times and production volume for these operations. This will create a cluster-a family of two NAME products. However, dynamic simulation subsequently verified this family, and its available machines are assigned. However, if the system does not have enough machines for this family, another product is selected in the group. The merging is repeated from another product pair. However, if the number of machines is sufficient for this cluster- the product family $\left(N A M E_{\alpha}\right)$ is re-checked with the new product (OPB matrix) using the LCS algorithm (blue arrows). The right arrow also represents this process, and thus a new product (e.g., $\mathrm{K} 7-\mathrm{OPA}$ ) and an already merged cluster of $\mathrm{K} 1 \mathrm{~K} 8$ products marked with the matrix $N A M E_{\alpha}$ enter the LCS algorithm. This process is repeated until all available machine capacity in the system is used. However, the algorithm is shown in Figure 3 only describes the merging process shown above, with the value of the standard production time T $\alpha$ and the typical production volume for a given time $n \_z$ being calculated for each cluster $N A M E_{\alpha}$ at the end of the algorithm. 


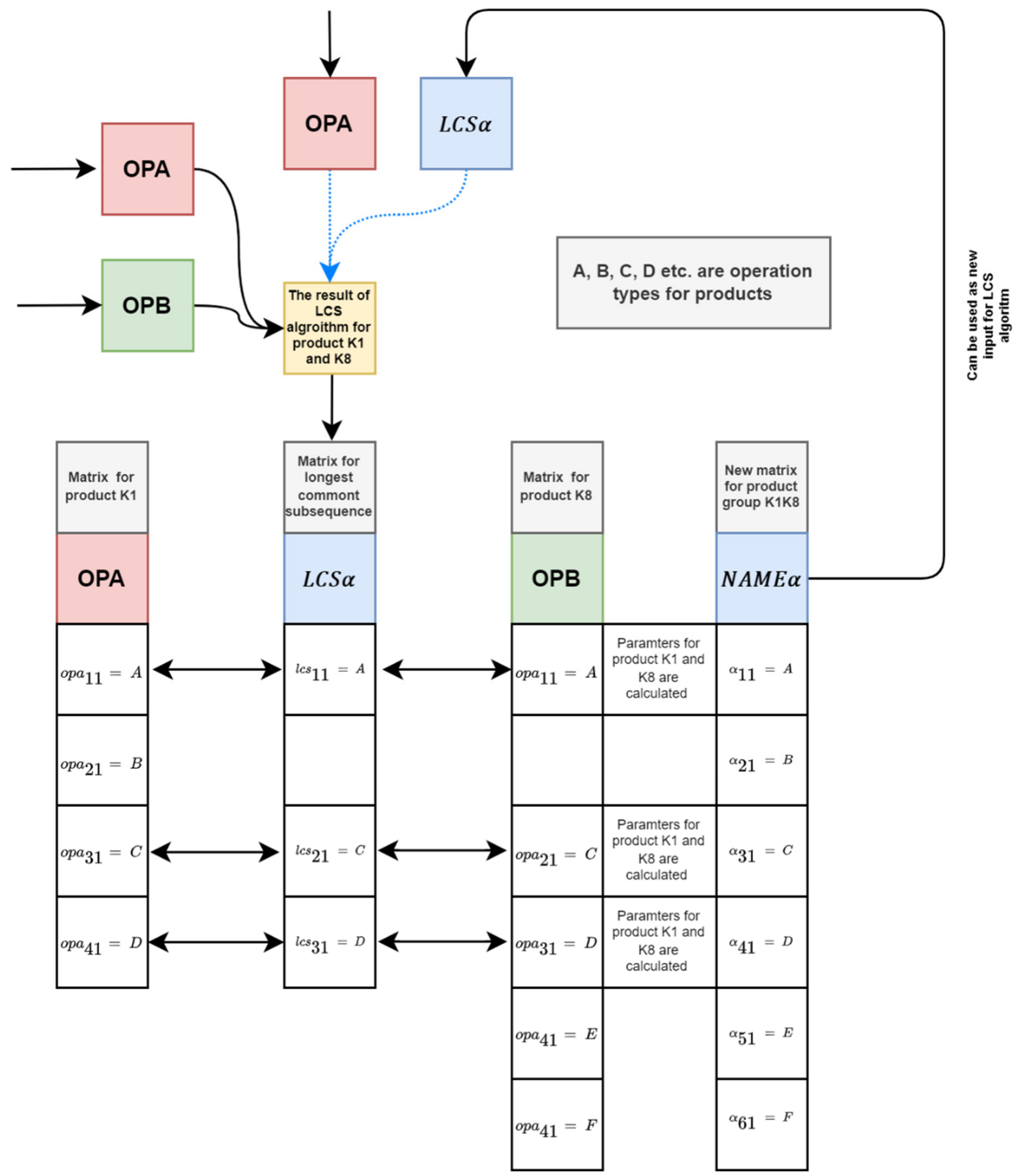

Figure 4. Demonstration of more detailed product family creation (based on the previous algorithm, Figure 3).

The last part of the described algorithm calculates the production volume for the individual production stages, which will produce the specified types of operations given by the matrix $N A M E_{\alpha}$. Therefore, each production stage is designed for a different type of operation, and a different amount of products will be processed on it. Therefore, from a capacity point of view, a specific production volume has to be recalculated for each stage and thus the operation. Moreover, the length of time $t k n$ varies between products, so it is necessary to determine the ordinary time $T \alpha$ during which the same proportion of the 
number of products of the product family is produced. Product family time is the minimum time from the set of all product production times assigned to a product family. At the end of time $T \alpha$, the production of the product (which corresponds to the calculation of the production volume for each stage of the operation) will be preceded by the calculation of the production volume for the product and for the specified period T $\alpha$ concerning the original time $t k n$. However, these production volumes are intended for a product, so it is necessary to calculate the production volume for each operating stage by adding up, depending on the types of products and operations assigned to the production stages.

The production configuration will be designed and compared with the simulation model in the next part of the algorithm. The criterion of this model will be primarily the fulfilment of the processing conditions of the specified production volume. Due to this condition, it is necessary to calculate the total entered production quantity. This quantity is calculated using all recalculated production volumes for the products. This calculated volume will then be the comparison criterion for meeting the conditions of the tested configuration.

(B) The first step of the second part of the product family module is to calculate the required number of devices for a specific operation of a given production/operation stage to determine the required configuration. The number of production stage devices depends on the calculated takt time and the rhythm of the whole manufacturing line. Both the takt time and the rhythm are values indicating the average time interval between the removals of two consecutive parts. However, the work line rhythm considers the production time reduced by the total time lost due to technical or organizational reasons. Time of losses due to breaks will not be assumed for this calculation and is therefore not included. Equipment failure due to technical reasons is not the subject of this part of the calculation but is considered in the line backup module. The last factor defined as the loss time is the line reconfiguration time. However, this time does not directly affect the capacity calculation and is therefore only considered when determining the total iteration time, which is not part of this article.

The calculated number of devices may not process the required products in a defined time. Therefore, it is necessary to verify the proposed configuration. Therefore, to verify the capacities using simulation, a correction factor $K_{p}$ was designed, which reduces the value of the line rhythm and thus increases the number of devices. The line rhythm is thus calculated based on the adjusted line rhythm pattern.

$$
r_{\alpha_{i p}}=\frac{T \alpha}{n \alpha_{i} * K_{p}}[\mathrm{~min} / \mathrm{pcs}],
$$

The synchronization coefficient can be calculated using a specified line rhythm for each operation. However, the sync factor formula needs to be adjusted. Several products of the product family pass through the production stage. The number of these products going through the operation must therefore divide the total time calculated for the products of the product family.

$$
\vartheta_{\alpha i_{p}}=\frac{t \alpha_{i j}}{L c_{i} * r_{\alpha_{i p}}}[1],
$$

By rounding the value of the coefficient upwards, we get an integer defining the total number of required workplaces for the given operation.

$$
w_{\alpha i_{p}}=\left\lceil\vartheta_{\alpha i_{p}}\right\rceil[1],
$$

The next part of the conversion of the displayed algorithm (see Figure 5) is the calculation of the sum of the total number of workplaces of the line. The stated value will be in the next module the assessment criterion of the feasibility of the configuration of the proposed cluster of product family $\alpha$. 


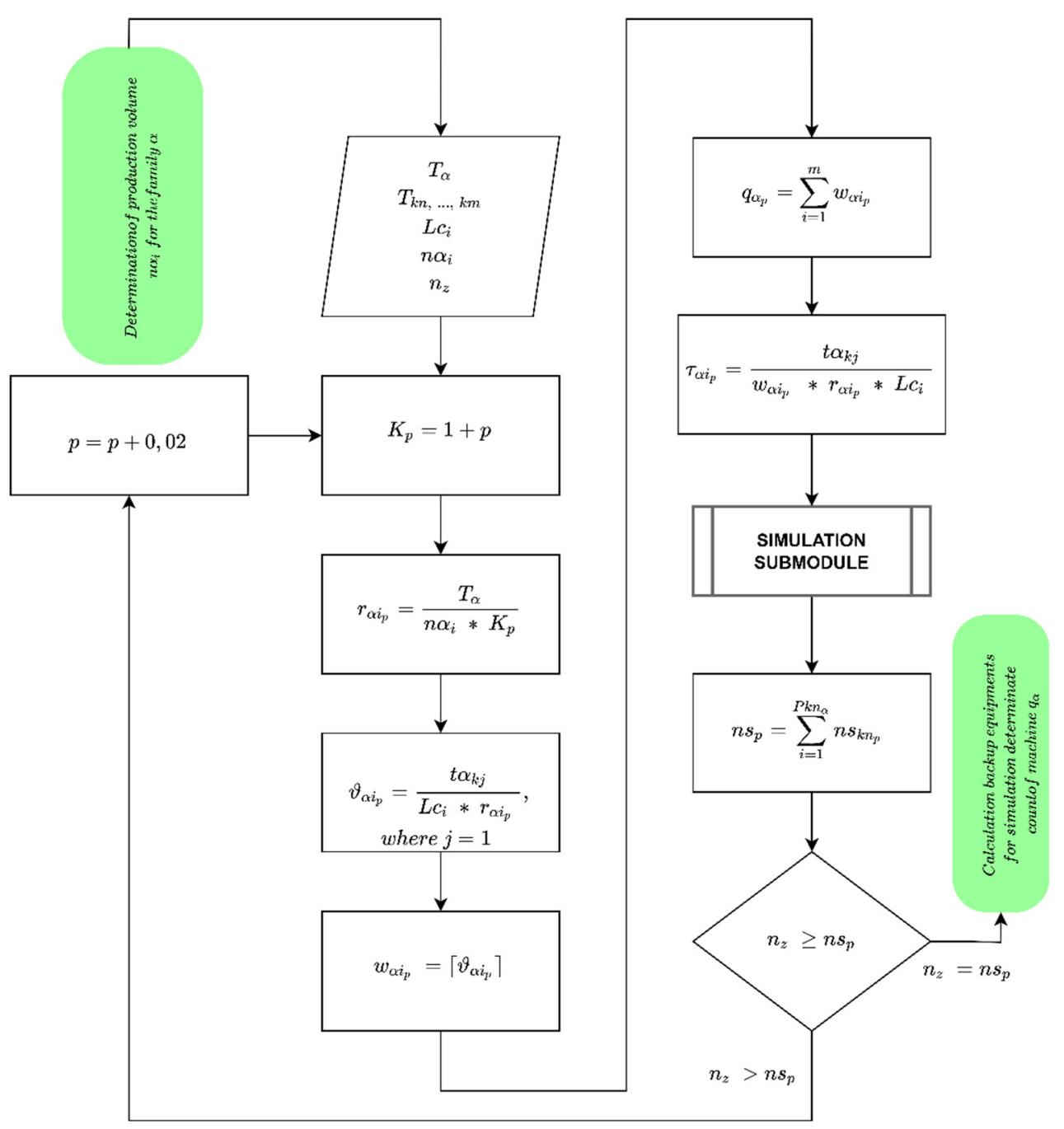

Figure 5. The second part of the module algorithm — the product family creation and resource availability.

As already mentioned, the proposed configuration needs to be verified in the next step, in the simulation submodule. The simulation was performed using the simulation software Tecnomatix Plant Simulation v. 14.2, Educational. A parametric simulation model was created to verify the proposed configurations. This model is described below. An essential aspect of the simulation is the number of processed products.

$$
n s_{p}=\sum_{i=1}^{p k n_{\alpha}} n s_{k n_{p}}[\mathrm{pcs}]
$$

The previous section determined the total amount of all entered production volumes $\left(n_{z}\right)$ for individual products $k_{n}$; this value is now compared with the simulated value of all processed product products $k_{n}\left(n s_{p}\right)$. If this condition is proper, the production configuration with the calculated number of devices $q_{\alpha_{p}}$ is suitable and allows the specified production volume to be produced.

$$
\begin{gathered}
q_{\alpha_{p}}=\sum_{i=1}^{m} w_{\alpha i_{p}}[\mathrm{pcs}], \\
n_{z} \geq n s_{p},
\end{gathered}
$$


If the condition does not apply, it is necessary to use the described correction coefficient. The increment value will cumulatively increase this coefficient after each non-compliance. The increment value was determined to be $p=0.02$ based on several experimental recalculations. Thus, the configuration is calculated and verified by simulation only after determining the configuration that can process the specified production volume in a defined time $T \alpha$.

$$
\begin{gathered}
K_{p}=1+p[1], \\
p=p+0.02
\end{gathered}
$$

Notes: The value of " $p$ " increases cumulatively.

A parametric simulation model (mentioned above) was created for the simulation submodule addressing the verification of the proposed product family configuration. The realization of the simulation model was performed in the Tecnomatix Plant Simulation software v. 14.2, Educational. A parametric simulation model can be used to identify a simulation model that allows changing the set functions and several entered parameters quickly. The RMS simulation model was designed to quickly mimic a change in a given configuration, product production volumes, and the total simulation time. These parameters vary depending on the tested product family and the correction factor. This coefficient is used to determine the optimal configuration. To better understand the mentioned submodule, the following simulation model and its use in the concept of the proposed methodology will be described in the following paragraphs.

The overall design of the methodology was created using the MS Excel software package in the VBA scripting language. Therefore, creating a communication link between MS Excel and the simulation software was necessary, which allows dynamic data exchange (DDE). DDE is a protocol set of messages and instructions. This protocol transfers messages between applications that share data and use shared memory for data exchange. The advantage of this solution lies in the straightforward implementation of the proposed solution in the MS Excel package. In addition to the DDE interconnection, the simulation model also contains its logic and elements, ensuring its independent functionality. The description of the functionality of the simulation model can therefore be logically divided into the following three parts:

(a) The basic logic of the simulation model lies in meeting the modularity criterion that defines the RMS concept. The model must also change the configuration dynamically depending on the values of the results calculated via MS Excel. Due to these conditions, the structure of the simulation model was created from individual production stages, at which a specific operation determined by the product family will always be processed. The products go through these production stages depending on whether they are to be processed at a given stage. This means that if the operation at a given stage is not intended for the incoming product, this product proceeds to the next production/operational stage. Data for the simulation model are imported in each simulation run with MS Excel software.

A critical specification of the created simulation model is its limitations concerning the production stages and the number of products. The first limitation of the simulation model is the total number of devices in the production stage. Each production stage in the created model contains a maximum of twenty devices. Moreover, the total number of stages of the model is twenty. Therefore, if the capacity calculations exceed these values, the simulation will not occur because the model would have to be extended by the required number of machines or stages. Another limitation is the number of incoming products, with the model can generate only ten types of products. However, for the conversion of the methodology data, the set parameters are sufficient, and it was not necessary to adjust the model for the described constraints. If necessary, the proposed simulation model can be extended or changed. Then working from a higher value of the mentioned parameters would be possible.

(b) The elements of the simulation model are shown in the schematic design of the model (see Figure 6). The schematic elements are identical to the proposed model in the 
Tecnomatix Plant Simulation software v. 14.2, Educational. Unlike the simulation model, the schematic design does not show all production stages because the individual stages are identical and do not need to be plotted.

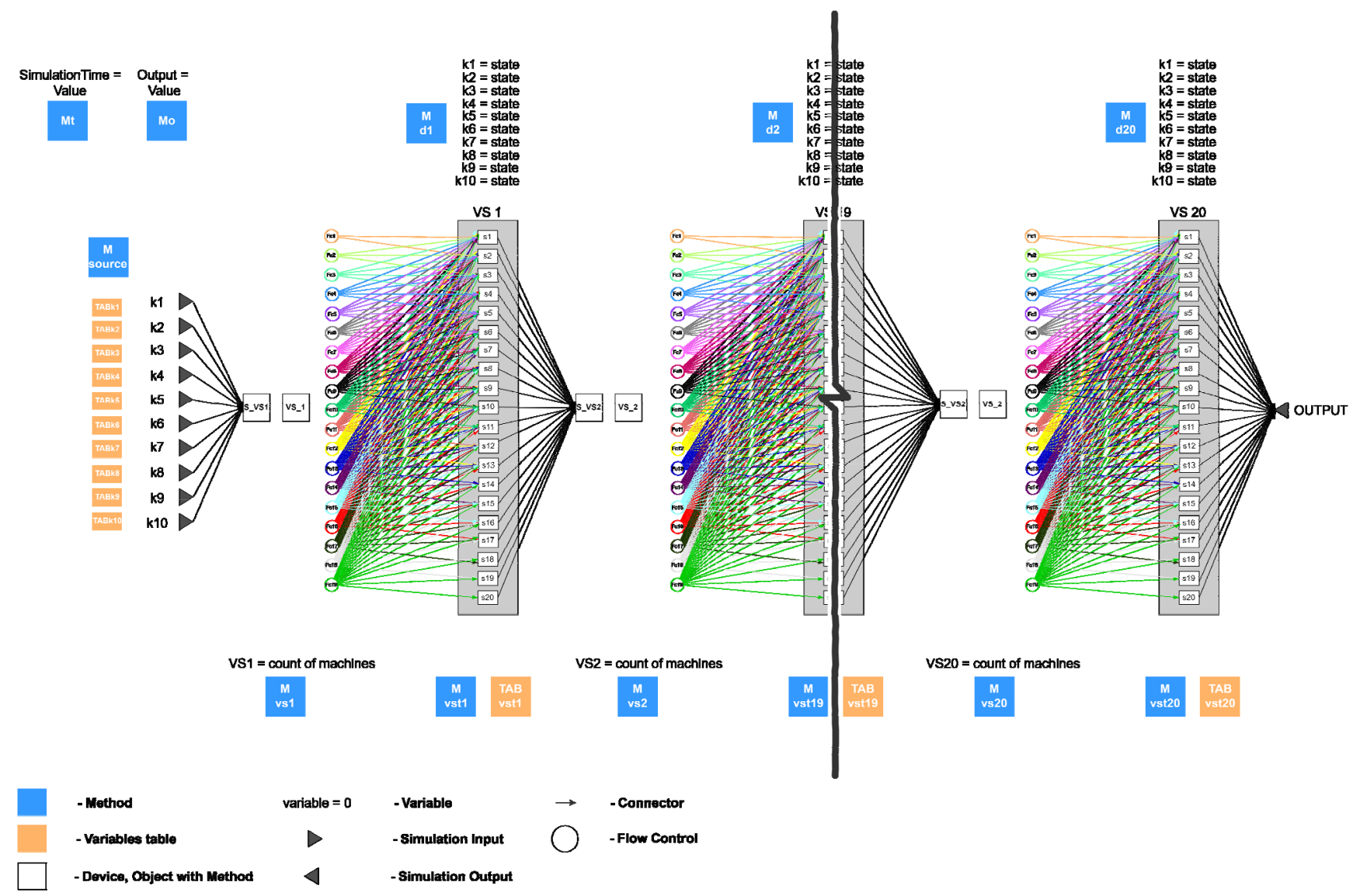

Figure 6. Schematic representation of the created simulation model.

The following paragraphs will describe the function and purpose of each element of the schematic model. The basis of the simulation model is the generation of input products. A method (MSOURCE) was created for input using the SimTalk 2.0 language. The method writes via the MS Excel parameter for the volume of the product types to the input tables (TABk1 to TABk10) for each product type separately. For example, product K1 is product volume $=450$ (in the first iteration), but in the next iteration of this methodology, it is product value $=150$; this parameter is written down to element TABk1. For product, K2 is situation equal, and the product volume is written down to element TABk2 etc.

After starting the simulation, these values are generated on the input, from where they pass to the element S_VS1. The element contains the output rule defined by the Md1 method and the input variables $\mathrm{k} 1$ to $\mathrm{k} 10$. The variables determine the state of the product transition through the operating stage based on data from MS Excel. The method assesses the transition of a given product to the production stage on the basis of an acquired value of 1 or 0 . If the product does not pass through the operating stage, it proceeds to the next element, S_VS2. If the variable reaches the value 1, the product will be processed at the operational stage, and thus proceeds to the element VS_1. The following element addresses the product only to the required number of devices based on the input data for the given production/operating stage. In this case, this is decided by the proposed method MVS1. Based on the value of the variable VS1, this method determines the path of the product to a specific material flow distributor (elements FC1 to FC19). The distributor element determines the number of machines used for processing products for the operating stage. If necessary, e.g., two devices, the products will go to the FC2 distributor; if necessary, three 
devices, the products will go to the FC3 distributor, etc. When one machine is needed, the products proceed directly to the machine element $\mathrm{S} 1$.

Another critical part of the simulation model is determining and recording operating times for specific products. Thus, the Mvst1 method reads the necessary data on the operating times processed at the production stage and writes them to be defined in the element table TABvst1. The table elements are permanently assigned to each machine in each stage, so the machines identify the operating time based on said table elements.

The next part is the Mt method, which, based on the SimulationTime variable, overwrites the simulation time with the time defined for the product family T $\alpha$. After starting the simulation, the last method Mo is activated, which has the task of writing the final volume of processed products into the variable Output. The result is then read back into MS Excel as the value $n_{s p}$. The resulting simulation model proposed in the Tecnomatix Plant Simulation software v. 14.2, Educational is shown in Figure 7.

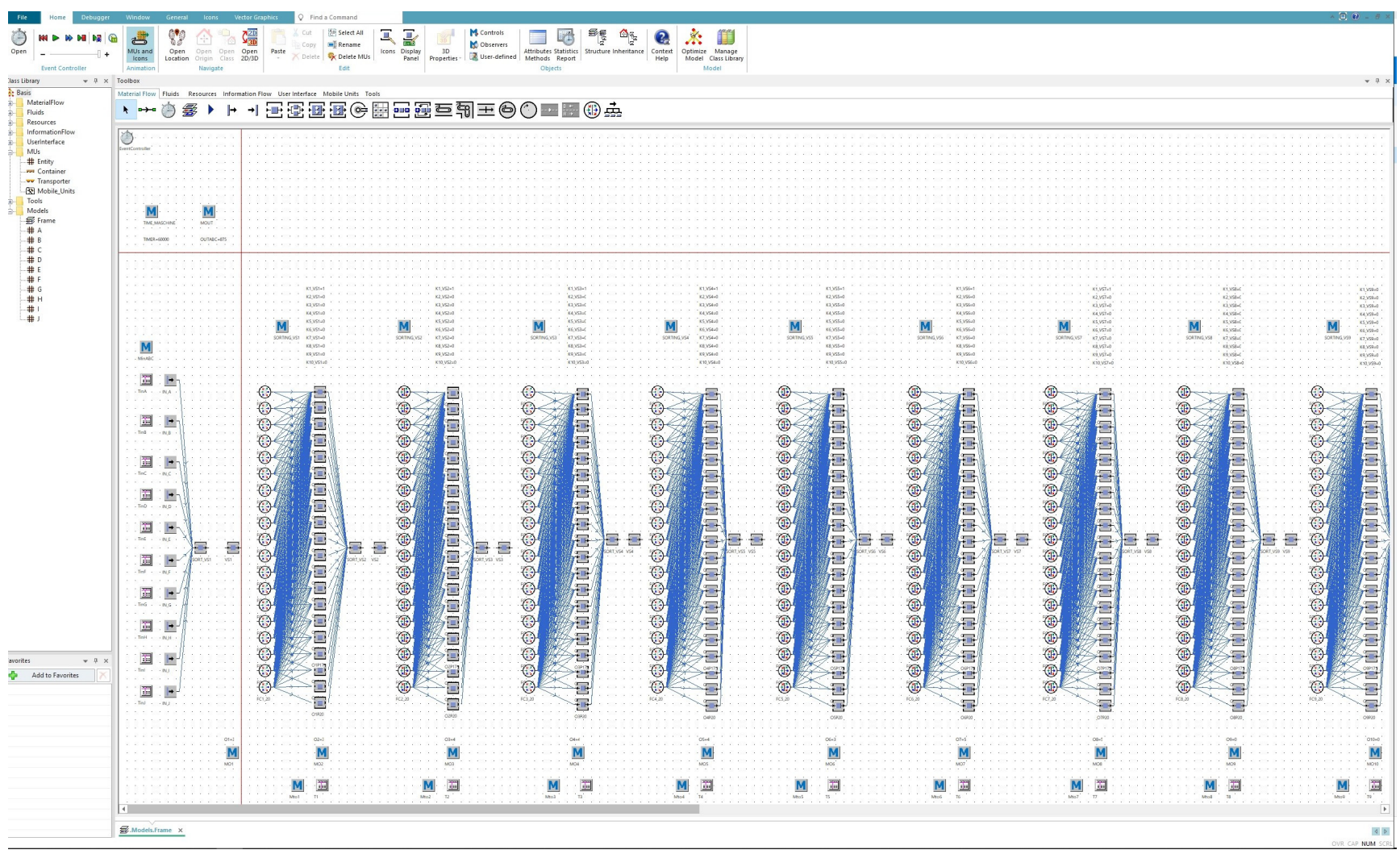

Figure 7. The simulation model was created to verify the proposed configurations.

(c) The last part of the simulation was the creation of data exchange of the simulation model and MS Excel via DDE. The simulation model is subject to the MS Excel package procedures using DDE. The functionality of the mentioned dynamic exchange is based on the execution of individual methods and direct writing of the determined values of MS Excel into the defined simulation variables. In MS Excel, the condition $n_{z} \geq n s_{p}$ (6) is then verified from the algorithm shown in Figure 4; if the condition is met $n_{z}=n s_{p}$, the calculation continues to the next part of the module (in our case section $C$ in text).

$\mathrm{C}$, the third part of the creation of the product family describes the backup calculations for the specified product family (Figure 8), while the availability of resources/equipment for this family is also determined in parallel. The calculation of the backup machine is based on the failure rates that occurred during the manufacturing of the previous product family. Suppose a fault has occurred in the set of machines in the previous iteration. In that case, there is a higher probability that this fault will occur again. Therefore, it is necessary to create a reserve in a backup machine. In general, two types of machine backup can be 
distinguished, namely cold and warm backup. In the case of a cold backup, the device is idle during a line failure condition, but the device starts if a line failure occurs. A cold backup of the machine at start-up time from idle always needs a specific start-up time, which can be referred to as $\Delta_{t z_{i}}$. Unlike cold backup, the warm backup is in continuous operation and does not need start-up time, but the problem can be the failure rate of the backup itself. The backup machine should have substitutability, especially for the operating stage where the highest failure rate occurred in the previous iteration. However, the most suitable variant with a high failure rate at several workplaces is a machine that provides a high degree of variability. In the following sections, we will focus on determining the machine's backup for a specific operating stage, regardless of the degree of variability of the backup machine.

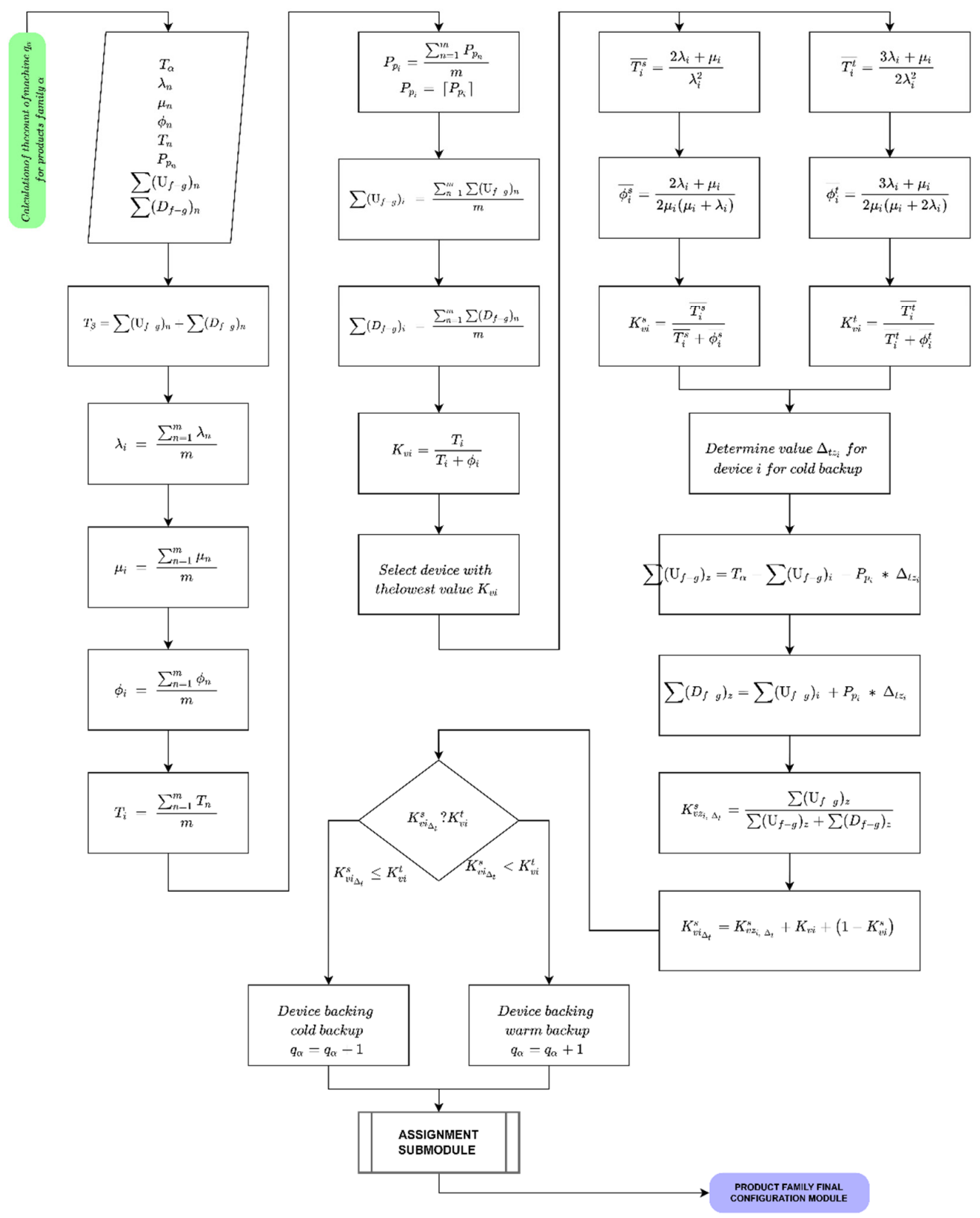

Figure 8. The third part of the module algorithm-The product family creation and resource availability.

The device backup calculation defines several input parameters, but they are mutually derivable, and it is therefore not necessary for all of them to be entered unconditionally. In this case, the basic input data are the mean time between faults $\left(T_{n}\right)$ and the mean 
time between repairs $\left(\Phi_{n}\right)$ for a specific machine, which was determined from the previous iteration. However, if they are not available, they can be expressed based on the following formulas:

$$
\begin{gathered}
T_{n}=\frac{\sum\left(U_{f-g}\right)_{n}}{P_{p_{n}}}[\mathrm{~min} .], \\
T_{n}=\frac{1}{\lambda_{n}}[\mathrm{~min} .], \\
\Phi_{n}=\frac{\sum\left(D_{f-g}\right)_{n}}{P_{p_{n}}}[\mathrm{~min} .], \\
\Phi_{n}=\frac{1}{\mu_{n}}[\mathrm{~min} .],
\end{gathered}
$$

For a defined total operating time $\sum\left(U_{f-g}\right)_{n}$ and faults $\sum\left(D_{f-g}\right)_{n}$, the general condition of equality to total time applies $T_{\beta}$ to the previous iteration during which the data were collected.

$$
T_{\beta}=\sum\left(U_{f-g}\right)_{n}+\sum\left(D_{f-g}\right)_{n}[\mathrm{~min} .],
$$

As mentioned in the previous paragraph, data are determined for each device separately due to the reconfiguration after each iteration. With a newly created product family, the equipment may belong to a different operating stage, thus changing the total value of the failure rates for the new line configuration. It is, therefore, necessary to calculate the average value of the entered data of specific devices for a given operating stage " $i$ ". The average value of each parameter is calculated as the proportion of the total number of devices $m$ in a given stage that the assignment submodule has assigned.

$$
\begin{gathered}
\lambda_{i}=\frac{\sum_{n=1}^{m} \lambda_{n}}{m}\left[\text { min. }^{-1}\right], \\
\mu_{i}=\frac{\sum_{n=1}^{m} \mu_{n}}{m}\left[\text { min. }^{-1}\right], \\
\Phi_{i}=\frac{\sum_{n=1}^{m} \Phi_{n}}{m}[\mathrm{~min} .], \\
T_{i}=\frac{\sum_{n=1}^{m} T_{n}}{m}[\mathrm{~min} .], \\
P_{p_{i}}=\left[\frac{\sum_{n=1}^{m} P_{p_{n}}}{m} \mid[1],\right. \\
\sum\left(U_{f-g}\right)_{i}=\frac{\sum_{n=1}^{m} \sum\left(U_{f-g}\right)_{n}}{m}[\mathrm{~min} .], \\
\sum\left(D_{f-g}\right)_{i}=\frac{\sum_{n=1}^{m} \sum\left(D_{f-g}\right)_{n}}{m}[\mathrm{~min} .],
\end{gathered}
$$

Subsequently, the utilization factor $K_{v i}$ can be determined for each operating stage " $i$ " from these average values. The next step is to determine the minimum value of the utilization factor from all calculated coefficients.

$$
K_{v i}=\frac{T_{i}}{T_{i}+\Phi_{i}}[1]
$$

The lowest value of the utilization factor determines the equipment and the operating stage with the highest failure rate during manufacturing in the previous iteration. The same backup device will therefore back up devices performing this operation. The final 
designing of the configuration also requires the determination of the backup type, and therefore in the next step, it is necessary to calculate the warm backup factor $K_{v i}^{t}$ and the cold backup factor $K_{v i}^{s}$. The calculated cold backup factor does not include the required start-up time of the device. Therefore, it is necessary to recalculate the factor with the specified value $\Delta_{t z_{i}}$ in the next section.

$$
\begin{gathered}
\overline{T_{i}^{s}}=\frac{2 \lambda_{i}+\mu_{i}}{\lambda_{i}^{2}}[\mathrm{~min} .], \\
\overline{\Phi_{i}^{s}}=\frac{2 \lambda_{i}+\mu_{i}}{2 \mu_{i}\left(\mu_{i}+\lambda_{i}\right)}[\mathrm{min} .], \\
K_{v i}^{s}=\frac{\overline{T_{i}^{s}}}{\overline{T_{i}^{s}}+\overline{\Phi_{i}^{s}}}[1], \\
\overline{T_{i}^{t}}=\frac{3 \lambda_{i}+\mu_{i}}{2 \lambda_{i}^{2}}[\mathrm{~min} .], \\
\overline{\Phi_{i}^{t}}=\frac{3 \lambda_{i}+\mu_{i}}{2 \mu_{i}\left(\mu_{i}+2 \lambda_{i}\right)}[\mathrm{min} .], \\
K_{v i}^{t}=\frac{\overline{T_{i}^{t}}}{\overline{T_{i}^{t}}+\overline{\Phi_{i}^{t}}}[1],
\end{gathered}
$$

Most machines need a short rise time, defined by the value $\Delta_{t z_{i}}$, which is not part of the cold backup usage recalculation. Assuming that $\Delta_{t z_{i}}$, is part of each failure ramp, it can be argued that it is the product of the number of machine failures $P_{p_{i}}$ and the defined rise time. This product can be deducted from the total operating time of the device and the total time $T_{\alpha}$, resulting in the value of the operation of the backup device. With a similar approach, we can calculate the downtime of the backup.

$$
\begin{gathered}
\sum\left(U_{f-g}\right)_{z}=T_{\alpha}-\sum\left(U_{f-g}\right)_{i}-P_{p_{i}} * \Delta_{t z_{i}}[\mathrm{~min} .] \\
\sum\left(D_{f-g}\right)_{z}=\sum\left(U_{f-g}\right)_{i}+P_{p i} * \Delta_{t z_{i}}[\text { min.] }
\end{gathered}
$$

The expected backup utilization factor $K_{v z_{i, \Lambda_{t}}}$ can be calculated with a defined rise time based on the estimated operating times and inactivity.

$$
K_{v z_{i, \Delta t}}^{s}=\frac{\sum\left(U_{f-g}\right)_{z}}{\sum\left(U_{f-g}\right)_{z}+\sum\left(D_{f-g}\right)_{z}}[1],
$$

Suppose we calculate the utilization factor of the backup device with a defined start-up time and add this value to the original utilization factor $K_{v i}$ of the operating stage " $i$ ". In that case, we obtain a value distorted by the backup device's missing failure rate. With the cold backup utilization factor $K_{v i}^{S}$ it can be assumed that this value contains the failure rate of the operating stage devices but also the failure rate of the backup device. However, the calculated value does not contain the value of the specified delay time, so it can be argued that the rest of the value of the utilization factor up to $100 \%$ is just the value of the missing failure rate. This balance must be deducted from the sum of the backup device coefficients and the operating stage factor. In this way, we get the real value of the cold backup utilization factor $K_{v i_{\Delta_{t}}}^{s}$ with the specified rise time for the defined operating stage. This procedure can be calculated based on the following formula:

$$
K_{v i_{\Delta_{t}}}^{s}=K_{v z_{i, \Delta_{t}}}^{s}+K_{v i}+\left(1-K_{v i}^{s}\right)[1],
$$


The last step is to evaluate the condition that compares the calculated cold and warm backup factors. In both cases, it is necessary to reserve equipment for the system (q_ $\alpha+1)$, but the difference is in the way the backup equipment is used in the manufacturing process of the product family. If the cold backup factor is higher, the used devices $q \alpha$ will be backed up by the cold backup principle. Otherwise, the selected backup device principle is the warm backup principle:

$$
\begin{gathered}
K_{v i_{\Delta_{t}}}^{S} ? K_{v i}^{t}, \\
q_{\alpha}=q_{\alpha}+1,
\end{gathered}
$$

\section{Results}

Due to the large scale of the overall solution, this article will be based on the study results of the designing of manufacturing lines using the principle of reconfigurability [20]. Therefore, only the results for the described module will be given.

To concretize the proposed solution, it can be stated that ten products with the designation K1-K10, were defined for the calculation. The size of the manufacturing system with the number of machines $Z Q=50$ was also defined. Specific types of operations have been defined for the products matrix $\left(N A M E_{k n}\right)$ for their processing, together with their operating $\left(t_{i j}\right)$, the number of pieces to be produced $\left(n_{k n}\right)$, as well as the manufacturing time defined by the customer $\left(C r_{t_{k n}}\right)$. The specific operations that the given system device can perform have also been defined (matrix $Z A=\left(o_{i j}\right)_{m}^{n=1}$ ), and thus specific devices are reserved for specific operations (S1-S50). These input data were then recalculated in the modules Capacity and Operational availability and Validation of product manufacturability in time. These models verified the feasibility of the specified products and transferred products meeting these criteria to the Product priority determination module. The resulting assignment sequence for a given iteration was determined in this module. A more detailed process of creation is not the subject of this study, and therefore only the final sequence for a given iteration of the solution is given.

$$
\Omega=\left\{\Omega_{k 1}, \Omega_{k 8}, \Omega_{k 2}, \Omega_{k 7}, \Omega_{k 4}, \Omega_{k 10}, \Omega_{k 5}, \Omega_{k 9}, \Omega_{k 3}, \Omega_{k 6}\right\},
$$

As mentioned above, the product family creation module results will only be described for the final product family configuration for the first iteration. Furthermore, only the results for the final sequence of the iteration will be given. Thus, the above description contains only the final solution because each sequence has an identical solution procedure. It is therefore not necessary to describe each one separately.

The product family creation algorithm begins with the first part, which involves creating product clusters and determining the production volume, as explained in the Method chapter. The LCS algorithm searches for the most extended standard sequence of operations of specified products for a specific product pair. Subsequently, the required production volume for each operating stage (operation) is recalculated separately. This calculation is necessary given the different times $t_{k n}$ and the different types of products assigned to a particular operating stage. Therefore, the first step is to determine the minimum expected processing time for the products of the T $\alpha$ product family. After defining this value, the updated production volume can be calculated for each product in the family. If we have a calculated production volume for each product, we can determine the production volume for a specific operating stage. Due to the future verification of the proposed configuration utilizing a simulation model, it is also necessary to calculate the total production volume. The results of all the values given are shown in Table 1.

Another part of the product family configuration design calculates the required number of machines, which decides the possibility of producing a product family with specified products. The calculation of the number of machines is subject to verification through a computer simulation performed in the Tecnomatix Plant Simulation software v. 14.2, Educational environment. The configuration design can therefore be divided into two 
parts: the calculation of the initial number of configuration machines and the configuration verification through simulation.

Table 1. The resulting values of the production volumes needed to process during a given iteration of a particular cluster of product family.

\begin{tabular}{|c|c|c|c|c|c|c|}
\hline $\begin{array}{c}\text { Production } \\
\text { Stages (i) }\end{array}$ & $\begin{array}{c}\text { Family } \\
\text { Products } \alpha\end{array}$ & $n \alpha_{i}$ (pcs) & Products & $t_{k n}$ (min.) & $\bar{n}_{k n}(\mathrm{pcs})$ & $x_{k n}$ (pcs) \\
\hline 1 & K1K8 & 875 & K1 & 1200 & 450 & 375 \\
\hline 2 & K1K8 & 875 & K8 & 1000 & 500 & 500 \\
\hline 3 & K7K1K8 & 1067 & K7 & 2500 & 480 & 192 \\
\hline 4 & K7K1K8 & 1067 & & & & \\
\hline 5 & K7K1K8 & 1067 & \multicolumn{4}{|c|}{$T \alpha=1000 \mathrm{~min}}$. \\
\hline 6 & K7K1K8 & 1067 & & & & \\
\hline 7 & K7K1K8 & 1067 & \multicolumn{4}{|c|}{$n_{z}=1067$ pcs } \\
\hline 8 & K7K8 & 692 & & & & \\
\hline
\end{tabular}

In the first phase, the work rhythm of the line configuration will be calculated using the Formula (1); during the initial recalculation, the increment of the correction coefficient is $p=0$ and thus $K_{p}=1$. Increasing the correction coefficient value will be performed only in the configuration verification part. After calculating the rhythm, the synchronization coefficient (2) and the total number of workplaces for the given operating stage (3) will be calculated. After calculating the stated values, the total number of workplaces for the proposed line configuration (5) can be added up.

The second phase of machine calculation includes the simulation submodule, while a detailed description of the module function and the simulation model itself was given in the second part-Methods. The value of processed products $n s_{p}$ will be available based on imported data on the number of machines and individual product production volume after the simulation run.

We determine the value of the simulated products as the sum based on the Formula (4). If this value satisfies condition (6), then the number of machines for the given configuration is satisfactory, i.e., there is no need to increase the value of the increment. If the condition does not apply, the increment increases based on the Formulas (7) and (8), and it is necessary to recalculate the rhythm of the line and the required number of machines. Thus, a qualifying configuration (6) contains several devices that can process all the specified products of the product family in a defined time. The calculation of the initial configuration and the results of the individual verifications by the simulation model are shown in the following Table 2.

After calculating the number of devices, the backups of the reconfigurable production line system are calculated. Variables that have been defined in the input module also enter this process.

As described in the previous chapter, the calculation of advances is part of creating a product family, and only the results for the creation of one calculated family of products will be given. This family is composed of products K7-K1-K8, and this is the first iteration of creating a product family in the proposed methodology. The required number of machines $q_{\alpha_{p}}=44$, was calculated for the mentioned family, while this value will be increased by one (25) in the form of warm or cold backup. The product configuration equipment also mentioned will consist of eight operating stages " $i$ ". The established machines will just be designed for the operating stage, which was the highest failure rate in the previous iteration. 
Table 2. Initial configuration and simulation model verifications.

\begin{tabular}{|c|c|c|c|c|c|c|c|c|c|c|}
\hline Production Stages (i) & & $r_{\alpha_{i_{p=0}}}$ & & \multicolumn{2}{|c|}{$\vartheta_{\alpha i_{p=0}}$} & \multicolumn{2}{|c|}{$w_{\alpha i_{p=0}}$} & \multicolumn{3}{|c|}{$\tau_{\alpha i_{p=0}}$} \\
\hline 1 & & 1.1429 & & \multicolumn{2}{|c|}{2.1875} & \multicolumn{2}{|c|}{3} & \multicolumn{3}{|c|}{0.72917} \\
\hline 2 & & 1.1429 & & \multicolumn{2}{|c|}{2.1875} & \multicolumn{2}{|c|}{3} & \multicolumn{3}{|c|}{0.72917} \\
\hline 3 & & 0.9372 & & \multicolumn{2}{|c|}{4.9793} & \multicolumn{2}{|c|}{5} & \multicolumn{3}{|c|}{0.99587} \\
\hline 4 & & 0.9372 & & \multicolumn{2}{|c|}{4.9793} & \multicolumn{2}{|c|}{5} & \multicolumn{3}{|c|}{0.99587} \\
\hline 5 & & 0.9372 & & \multirow{2}{*}{\multicolumn{2}{|c|}{$\begin{array}{l}5.6907 \\
56907\end{array}$}} & \multicolumn{2}{|c|}{6} & \multicolumn{3}{|c|}{0.94844} \\
\hline 6 & & 0.9372 & & & & \multicolumn{2}{|c|}{6} & \multicolumn{3}{|c|}{0.94844} \\
\hline 7 & & 0.9372 & & \multicolumn{2}{|c|}{4.2680} & \multicolumn{2}{|c|}{5} & \multicolumn{3}{|c|}{0.85360} \\
\hline \multirow[t]{2}{*}{8} & & 1.4451 & & \multicolumn{2}{|c|}{4.4980} & \multirow{2}{*}{\multicolumn{2}{|c|}{$\begin{array}{c}5 \\
38\end{array}$}} & & 0.89960 & \\
\hline & & & & \multicolumn{2}{|c|}{$q_{\alpha_{p}}$} & & & & & \\
\hline$K_{p}$ & 1.00 & 1.02 & 1.04 & 1.06 & 1.08 & 1.10 & 1.12 & 1.14 & 1.16 & 1.18 \\
\hline$q_{\alpha_{p}}(\mathrm{pcs})$ & 38 & 40 & 40 & 42 & 42 & 42 & 43 & 43 & 43 & 44 \\
\hline$n_{z}(\mathrm{pcs})$ & \multicolumn{10}{|c|}{1067} \\
\hline$n s_{p}(\mathrm{pcs})$ & 972 & 989 & 989 & 1005 & 1005 & 1005 & 1038 & 1038 & 1038 & 1067 \\
\hline$n_{z} \geq n s_{p}$ & no & no & no & no & no & no & no & no & no & yes \\
\hline
\end{tabular}

The failure rate data from the previous iteration are, in this case, randomly generated data within a specific, predefined range of possible failure rates. The primary input data for the calculation of the machine backup are the mean time between failures and the mean time between repairs. If the data are not entered directly, they can be derived according to Formulas (1)-(4). The values of all parameters listed in the previous formulas were generated for each system machine separately. However, these data are extensive and cannot be explicitly mentioned in this article. The generation of fault time values of the machine depends on conditions (5), where the input data of the possible fault variance $\left(P_{p_{n}}\right)$ and the determined fault time $(T \beta)$ are as follows:

$$
\begin{gathered}
T \beta(\min .)=1000, \\
P_{p_{n}}=(0,30),
\end{gathered}
$$

The previous section gave the specific number of machines for the proposed product family composed of specific products (state number, side part or something). However, it is necessary to find out the changed machine classification for the transformed operating stages for this newly designed configuration. From this point of view, it is necessary to use the assignment submodule, which will be used again even after defining the device backup. We can calculate the average values of the parameters defined for the operating stage for specific machines based on this approach. Information about the assigned machines from the assignment submodule will be used to calculate the average values. Therefore, the resulting average values are calculated using Formulas (6)-(12). From the results obtained, shown in Table 3 below (note the line marked in grey represents the lowest utilization factor $K_{v i}$ ), it is possible to calculate the utilization factor for each operating stage. We calculate the utilization factor using the Formula (13).

\begin{tabular}{|c|c|c|c|c|c|c|c|c|}
\hline $\begin{array}{c}\text { Production } \\
\text { Stages (i) }\end{array}$ & $\begin{array}{c}\lambda_{i} \\
\left.\text { (min. } .^{-1}\right)\end{array}$ & $\begin{array}{c}\mu_{i} \\
\left.\text { (min. }^{-1}\right)\end{array}$ & $\begin{array}{c}T_{i} \\
\text { (min.) }\end{array}$ & $\begin{array}{c}\Phi_{i} \\
\text { (min.) }\end{array}$ & $\underset{(\operatorname{min.})}{\sum\left(U_{f-g}\right)_{i}}$ & $\begin{array}{c}\sum\left(D_{f-g}\right)_{i} \\
(\text { min.) }\end{array}$ & $\boldsymbol{P}_{p_{i}}$ & $K_{v i}$ \\
\hline 1 & 0.0239 & 0.0339 & 41.9048 & 29.5238 & 586.6667 & 413.3333 & 14 & 0.5867 \\
\hline 2 & 0.0403 & 0.0215 & 24.8095 & 46.6190 & 347.3333 & 652.6667 & 14 & 0.3473 \\
\hline 3 & 0.0313 & 0.0254 & 31.9857 & 39.4429 & 447.8000 & 552.2000 & 14 & 0.4478 \\
\hline 4 & 0.0278 & 0.0511 & 35.9778 & 19.5778 & 647.6000 & 352.4000 & 18 & 0.6476 \\
\hline 5 & 0.0270 & 0.0459 & 37.0588 & 21.7647 & 630.0000 & 370.0000 & 17 & 0.6300 \\
\hline 6 & 0.0478 & 0.0375 & 20.9206 & 26.6984 & 439.3333 & 560.6667 & 21 & 0.4393 \\
\hline 7 & 0.0148 & 0.0174 & 67.4500 & 57.5500 & 539.6000 & 460.4000 & 8 & 0.5396 \\
\hline 8 & 0.0403 & 0.0359 & 24.7895 & 27.8421 & 471.0000 & 529.0000 & 19 & 0.4710 \\
\hline
\end{tabular}

Table 3. Utilization factors. 
From the results, it can be concluded that the lowest value of the utilization factor is reached by production stage 2 . Therefore, it will be necessary to design a machine backup for this workplace. The machine can be backed up in a cold or warm state. The type of deposit can be decided based on comparing the values of the coefficients of use of cold and warm backup. First, we calculate the utilization factor for the cold backup using Formulas (14)-(16). The following is the calculation of the value of the warm backup factor, in which formulas will calculate (17)-(19). However, the above calculations for the cold deposit do not contain the onset time $\Delta_{t z_{i}}$ and their value is therefore not relevant. For this reason, it is necessary to determine the rise time of the backup machines and recalculate the resulting value of the cold backup with the calculated rise time. In the first part of the calculation, it is necessary to calculate the backup machines total estimated operating time and idle time according to (20) and (21). Based on the above, it is necessary to recalculate the assumed utilization factor of the backup machine (22). It is possible to determine the final utilization factor of the cold backup at the specified start-up time of the backup machine. This value is calculated using the Formula (23). Based on the achieved results, we can make a final comparison of cold and warm backup coefficients. Machine reservation will be necessary for both backup cases, but in terms of the final configuration designing, a difference in the achieved results of the proposed line can be expected. The backup principle for the specified operating stage is evaluated based on condition (24), the fundamental calculated values of the factor and the entered value of the rise time being shown in the following Table 4 (note the line marked in grey represents a cold backup $\left.K_{v i_{t}}^{S}\right)$.

Table 4. Rise time factor.

\begin{tabular}{cc}
\hline Calculated Parameters & Parameters Value \\
\hline$\Delta_{t z_{i}}(\min )$. & 2 \\
$\overline{T_{i}^{s}}(\min )$. & 62.8221 \\
$\Phi_{i}^{s}(\min )$. & 38.5229 \\
$K_{v i}^{s}$ & 0.6199 \\
$\bar{T}_{i}^{t}(\min )$. & 43.8158 \\
$\Phi_{i}^{t}(\min )$. & 32.5149 \\
$K_{v i}^{t}$ & 0.5741 \\
$K_{v i_{\Delta_{t}}}$ & 0.5919 \\
\hline
\end{tabular}

Based on the achieved results, it can be said that the value of the rise time in the specified duration affected the decrease in the value of the cold backup utilization factor. However, the cold backup principle will be used for backup for its final value. Therefore, the total number of devices will be increased by one backup device in the form of a cold backup. After this step, the assignment module again checks the reservation of all machines needed for the configuration with the addition of one machine. The results of the assignment submodule showed that the sum of the total number of unassigned facilities is equal to zero in this case. Thus, a reservation of machines was made for all operations of individual stages. The resulting configuration with the specific names of the assigned manufacturing facilities is shown in Figure 9. On the following website [32] it is possible to find information on the reproducibility of the results for other researchers who want to take this area further. 


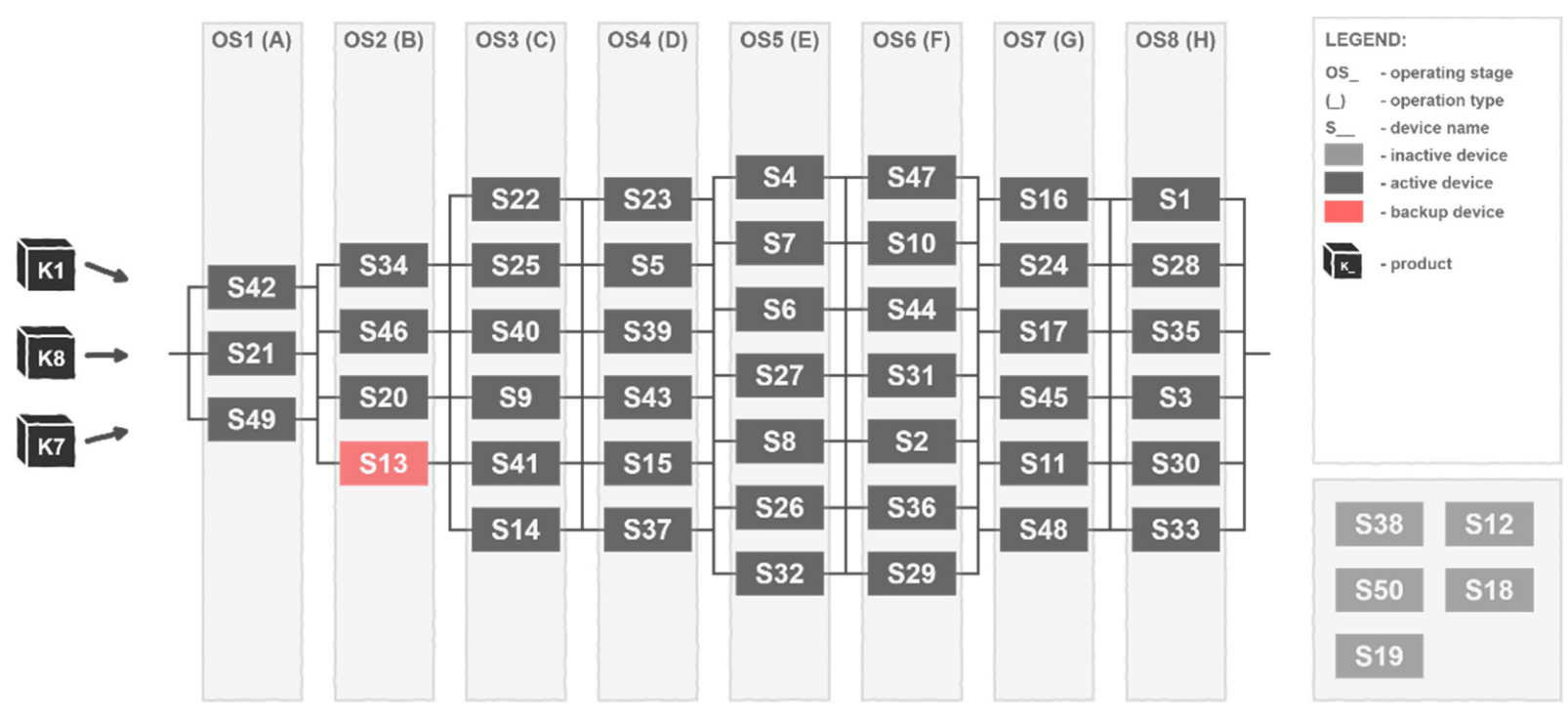

Figure 9. The final solution configuration.

\section{Discussion}

The essential starting point for solving the problem, which is addressed in this article, was the need to apply machine backup for the methodology described in the study: The design of manufacturing lines using the principle of reconfigurability [26]. As mentioned in the chapters above, common approaches were insufficient to back up a reconfigurable system. Therefore, it was necessary to specifically adapt the fundamental mathematical relationships and calculation logic for this system. Prior to applying the relationships, an overview of the literature dealing with the calculation of advances for reconfigurable manufacturing systems was created.

The modified mathematical relationships for the created product family designing algorithm were first independently verified by recalculation with randomly generated values. Only after this verification of the partial mathematical model was the application in the methodology algorithm followed. The previous results show that adjusting the fundamental relationships allows a simple algorithmization and determination of the need for backup for a specific manufacturing stage of the reconfigurable manufacturing system. The proposed algorithm can be extended by determining the backup for other operating stages of the manufacturing system, e.g., depending on the rising values of the order of the determined utilization factor. In the mentioned calculations, the utilization was also the calculation of the utilization coefficient with the onset time $\Delta_{t z_{i}}$. This will allow a more accurate determination of the utilization coefficient during cold backup. However, this parameter could be more complex, determined using computer simulation, but the proposed methodology did not require a high variability of input parameters $\Delta_{t z_{i}}$. However, in real manufacturing systems, this rise time can vary considerably for each failure, and also the duration of the failure would be a random variable. However, these new parameters could be fitted to the existing mathematical model. However, the mentioned algorithm did not include these other parameters, because it was necessary only for its primary verification and subsequent application in the methodology.

The application of the methodology creates a configuration that directly considers the basic principles of reconfiguration in its designing. Through the partial algorithm modules, the manufacturing system adaptability is also considered at the level of a specific line. Another vital part of the methodology is the direct verification of each proposed configuration using computer simulation [33], which is part of the overall concept of the application. Therefore, research in this area can lead to manufacturing systems capable of predicting customer needs and making independent decisions even in the case of more complex strategic decisions. These systems can be based on copying patterns from nature 
and fine-grained modularity. However, with the system's increasing number of modular elements, it can be expected to increase its adaptability, efficiency, and response speed. The declining granularity of modules and intelligence in factories is a prerequisite for the advent of nanotechnology and artificial intelligence, which will significantly change the way current manufacturing systems work.

Reconfigurable manufacturing systems have been introduced to react quickly and effectively to such competitive market demands through modular and scalable designing of the manufacturing system on the system level and on the machine components' level [34]. Reconfigurable manufacturing systems represent a new area of research globally, including the ability to reconfigurability, modularity, autonomy, adaptation to customer needs, rapid change in functionality and capacity, and rapid commissioning. They connect real and virtual environments and are a source of competitive advantage in a selected part of manufacturing systems like product innovation, production processes, and production systems [35,36]. Good process management in factories has become essential to ensuring sustainable productivity growth and competitiveness. Production in the factories will be provided in newly designed production systems. Future production systems must function as adaptive systems. They also need to flexibly change their capacity and functions to meet multiple criteria, such as reconfigurability, autonomy, intelligence, integrability, and more.

This manuscript is also in the context of solved scientific-research activities of the manuscript authors, who participate in the solution of two university grant projects in the field of research in the field of new approaches to advanced industrial engineering to support the development of an intelligent factory; and the field of 3D printing of spare parts in technical service. These areas complement and develop with each other.

\section{Conclusions}

The proposed methodology is a partial step for implementing new approaches to designing a system that quickly adapts to market conditions. The proposal also envisages extending the above criteria to create a more comprehensive system. The methodology designing process also envisages various concepts of a reconfigurable production system and can thus serve as a basis for different solutions in different areas and types of production systems. The proposed methodology will become essential for designing reconfigurable manufacturing systems with the construction of warm or cold machine backup. Without designing and implementing these advances in production processes [37], achieving the required manufacturing systems will be challenging due to various risks that may adversely affect future production systems and their processes. The 21st century will be characterized by developing and implementing the so-called smart and innovation solutions in all areas of human life, including the economy.

The proposed methodology is the initial stage of research in this area. This solution is currently being processed into an individual application combining all modules, including Cluster analysis and simulation, into a single software solution, which is a necessary measure for the subsequent extension of the methodology. In the mentioned example, certain limitations were given mainly due to the insufficient possibilities of the VBA language in the MS Excel package. By using the standard python programming language, these limitations will be removed. This improved version will plan the production of product families and schedule machines in any number of iterations. These iterations will later also be branched on the basis of several criteria, the aim being to select the optimal branch for the current requirements of the factory. To test different scales of the system machines, universality and variants of the produced products and the results will be verified by a more complex simulation taking into account the failure rate of the machines and equipment. The aim is to link the methodology to the existing algorithm for a modular production line [38] which will determine the more precise time aspect of the system reconfiguration. 
Author Contributions: Conceptualization, V.V., M.F. and M.G.; methodology, V.V. and M.F.; software, V.V. and M.B.; validation, V.V. and B.F.; formal analysis, M.B.; investigation, M.G.; resources, V.V. and M.F.; data curation, V.V.; writing-original draft preparation, V.V. and M.F.; writing-review and editing, V.V. and M.F.; visualization, M.B. and K.Š.; supervision, M.F. and V.V.; project administration, M.G.; funding acquisition, M.G. and B.F. All authors have read and agreed to the published version of the manuscript.

Funding: This work was supported by the Slovak Research and Development Agency under the Contract no. APVV-19-0305.

Institutional Review Board Statement: Not applicable.

Informed Consent Statement: Not applicable.

Data Availability Statement: The data presented in this study are available on request from the corresponding author. The full text of data is not publicly available due to company privacy.

Acknowledgments: The authors would like to express their appreciations to the anonymous reviewers, the editors and this work was supported by the Slovak Research and Development Agency under the contract No. APVV-19-0305 and APVV-16-0488.

Conflicts of Interest: The authors declare no conflict of interest.

\section{Nomenclature}

This nomenclature incorporates the meaning of all variables.

\begin{tabular}{|c|c|}
\hline $\begin{array}{l}C r_{t_{k n}} \\
n_{k n}\end{array}$ & $\begin{array}{l}\text { customer-defined time required to deliver the product } k_{n},[\mathrm{~min} .] \\
\text { production volume of the product } k n \text { defined by the } \\
\text { customer, }[\mathrm{pcs}]\end{array}$ \\
\hline$T_{k n}=\left(t_{i j}\right)_{m=P O C P_{k n}}^{n=1}$ & product operating time matrix $k n$, [min.] \\
\hline $\mathrm{POCP}_{k n}$ & total number of operations of the product $k n$ \\
\hline$N A M E_{k n}=\left(\text { name }_{i j}\right)_{m=P O C P_{k n}}^{n=1}$ & matrix of product $k n$ operation types \\
\hline$Z A=\left(o_{i j}\right)_{m}^{n=1}$ & matrix of all feasible operations of the production system \\
\hline$P=\{k 1, k 2, k n, \ldots\}$ & the set of all current products entered into the system \\
\hline$Z Q$ & total number of system devices, $[\mathrm{pcs}]$ \\
\hline$\xi_{k n}$ & $\%$ of technologically necessary failures for the product \\
\hline$S p_{k n}$ & $\begin{array}{l}\text { the total number of identical types of production system and } \\
\text { product } k n \text { operations }\end{array}$ \\
\hline$K_{k n}$ & $\begin{array}{l}\% \text { consistency between types of product } k n \text { operations and all } \\
\text { feasible processes of the production system, [\%] }\end{array}$ \\
\hline $\bar{n}_{k n}$ & $\begin{array}{l}\text { production volume of the product } k n \text { increased by } \% \text { of } \\
\text { technologically necessary failures, [pcs] }\end{array}$ \\
\hline$R e_{t_{k n}}$ & the time actually required to produce the product $k n$, [min.] \\
\hline$\left(t_{i j}\right)_{k n}$ & $\begin{array}{l}\text { time of the } i \text {-th operation of the product } k n \text {, element of the matrix } \\
T_{k n} \text {, [min.] }\end{array}$ \\
\hline$t_{k n}$ & final production time for the product $k n,[\mathrm{~min}]$. \\
\hline$C R$ & $\begin{array}{l}\text { critical ratio determining the last processing time of the } \\
\text { product } k n\end{array}$ \\
\hline$w_{k n_{i}}$ & $\begin{array}{l}\text { the total required number of devices for a given operation " } i \text { " and } \\
\text { product } k n\end{array}$ \\
\hline$q_{k n}$ & the sum of all necessary equipment for the product $k n$, [pcs] \\
\hline & the total number of assigned machines for the calculated value \\
\hline${ }^{P} p$ & $q_{k n}$ (the result of the assignment submodule), [pcs] \\
\hline$\dot{q}_{k n}$ & the sum of all required equipment for the product $k n,[\mathrm{pcs}]$ \\
\hline $\operatorname{Min}_{t_{k n}}$ & $\begin{array}{l}\text { minimum product production time } k n \text { with maximum use of } \\
\text { available resources, [min.] }\end{array}$ \\
\hline
\end{tabular}




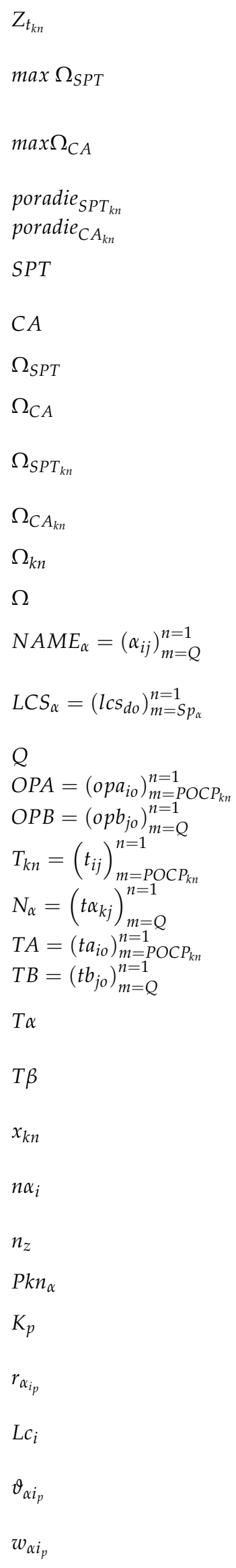

the residual production time of the product $k n$, by which the production process can be shortened as much as possible, [min.] the maximum weight value of the production time sorting criteria $t_{k n}$; value $\max \Omega_{S P T}$ is given at intervals $\langle 0 ; 1\rangle$ the maximum weight value of the product similarity criterion $k n$ based on the types of operations; value $\max \Omega_{S P T}$ is given at intervals $\langle 0 ; 1\rangle$

the product $k n$ rank value defined from the SPT set

product rank value $k n$ from the set $C A$

a group representing the order of products $k n$ in terms of length of time $t_{k n}$

a group representing the order of products in terms of product $k n$ similarity based on types of operations

unit weight index sorting criteria length of production times $t_{k n}$ unit weight index product similarity criteria $k n$ based on types of operations

weight index sorting criteria length of production times $t_{k n}$ for the product $k n$

weight index product similarity criteria $k n$ based on types of operations for product $k n$

total weight index for both requirements for the product $k n$ the set of entire sequences defining the order of assignment of products $k n$ to the product family $\alpha$ matrix of cluster operation types $\alpha$

matrix of common successive operations of two compared matrices $N A M E_{k n}$ or $N A M E_{k n}$ and $N A M E_{\alpha}$. Value $L C S_{\alpha}$ is the result of the algorithm LCS (Longest Common Subsequence) number of all functions of the matrix product $N A M E_{\alpha}$ matrix of operation types for the input element (product) an array of transaction types for a cluster/qualifying product product $k n$ operating time matrix matrix of burst operating times $\alpha$ operating time matrix for incoming element (product) an operating time matrix for a cluster/qualifying product the minimum collective production time of selected products of the family $\alpha$, [min.]

minimum joint production time of selected $\beta$ family products from the previous iteration, [min.]

new production volume for a product $k n$ for a defined period $T \alpha,[\mathrm{pcs}]$

production volume for a given operational production stage $i$, [pcs]

the sum of all entered production volumes for individual products $k n$, [pcs]

the total number of $k n$ products that is part of the cluster $\alpha$, [pcs] correction coefficient taking values at the interval $\langle 1, \infty)$ from by increment $p$

linework rhythm for the given operating production stage $i$ even at the specified increment $p$

the number of products in the product family going through the operational production stage $i$

synchronization coefficient for the given operation production stage $i$ even at the specified increment $p$

the total number of required workplaces for the given operating production stage $i$ even at the specified increment $p$ 


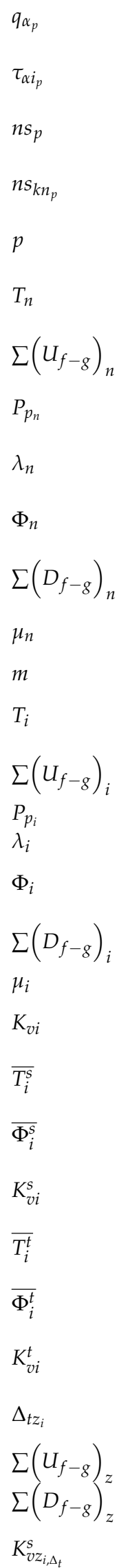

the total number of workplaces for the proposed configuration of the $\alpha$ product family at the specified increment $p$, [pcs] time utilization of the workplace for the given operational production stage $i$ even at the specified increment $p$ the simulation-determined sum of all processed products of $k n$ products at a given increment $p,[\mathrm{pcs}]$

simulation determined value of processed products of the product $k n$ at the specified increment $p$, [pcs]

the increment of the value of the correction factor determined by the conversion

meantime between failures for device $n$ determined for the period of the previous iteration

the total operating time of the device $n$ determined for the period of the previous iteration, [min.]

the number of faults for device $n$ determined in the last iteration period

fault intensity for device $n$ determined for the period of the previous iteration

meantime between repairs for device $n$ determined for the period of the previous iteration

total equipment failure time $n$ determined for the period of the previous iteration, [min.]

repair intensity for device $n$ determined for the period of the previous iteration

the number of devices of a given operational production stage $i$ average mean time between failures for the operating production stage $i$

average total operating time for the operating production stage $i$, [min.]

the average number of failures of the operating production stage $i$ the average failure rate for the operating production stage $i$ average mean time between corrections for the operating production stage $i$

average total failure time for the operating production stage $i$, [min.]

average correction intensity for the operational production stage $i$ machine utilization factor for the operating production stage $i$ calculated for the period of the previous iteration average mean time between failures for the operating production stage $i$ backed up by cold backup average mean time between corrections for the operating production stage $i$ backed up by cold backup utilization factor for the operating production stage $i$ backed up by cold backup

average mean time between failures for the operating production stage $i$ backed up by warm backup

the average mean time between repairs for the operating production stage $i$ and backed up by a warm backup utilization factor for operating production stage $i$ backed up by warm backup the rise time of the backup device for the operating production stage $i$

the total estimated operating time of the backup device the total estimated idle time of the backup device the assumed utilization factor of the backup device with the specified rise time $\Delta_{t z_{i}}$ 


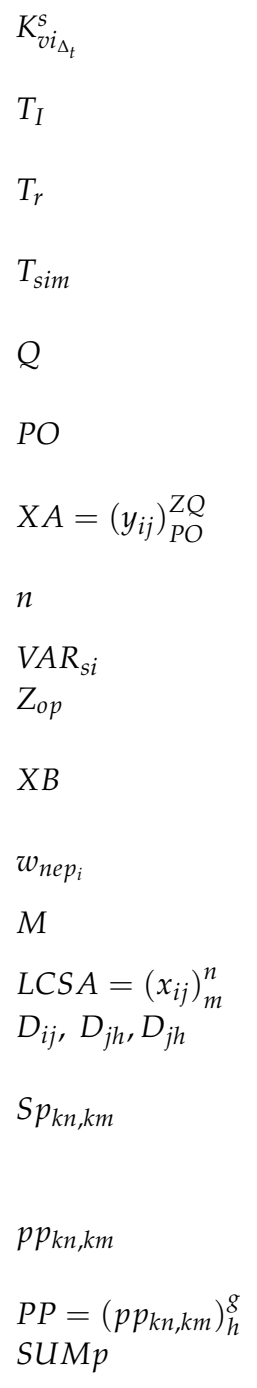

utilization factor for the operating production stage $i$ and backed up by a cold backup with a specified rise time $\Delta_{t z_{i}}$ the total time of the product family, taking into account the reconfiguration time for the current iteration, [min.] the time required to reconfigure the original configuration to the configuration specified by the new product family, [min.] the time necessary for the specified product family defined by the simulation [min.]

the total number of all product operations in the cluster $\alpha$, in the case of assigning only one product we use $P O C P_{k n}$ total number of matrix operations $Z A$, which the production system can perform matrix representing the feasibility of a given operation $i$ on the machine $j$ for all types of operations and equipment of the system a variable representing the order of assigning operations to devices

a sum of operations $j$, which the device $s$ can perform a sum of equipment $i$ available to carry out the operation op matrix defining the feasibility of the given operation $i$ on the machine $j$. For operations defined by a matrix $N A M E_{\alpha}$ or matrix $N A M E_{k n}$ depending on the use of the submodule number of unassigned devices for the operation $i$, [pcs] matrix of all possible operations $j$, which the machine $i$ can perform

LCS algorithm function matrix

cluster analysis distance measures

the total number of operations of the matrix $L C S_{\alpha}$ defining the most extended common sequence of operations of the product pair $k n$ and $k m$

degree of similarity of a couple of given products $\mathrm{kn}$ and $\mathrm{km}$, while the value can be defined as an element of the matrix of mutual similarities of all given products matrix of mutual similarities of all specified products the total number of all selected products $k n$ of the set $P$

\section{References}

1. Battaïa, O.; Dolgui, A.; Guschinsky, N. Optimal cost design of flow lines with reconfigurable machines for batch manufacturing. Int. J. Manuf. Res. 2020, 58, 2937-2952.

2. Koren, Y. The Global Manufacturing Revolution; John Willey \& Sons: Hoboken, NJ, USA, 2010.

3. Micieta, B.; Staszewska, J.; Kovalsky, M.; Krajcovic, M.; Binasova, V.; Papanek, L.; Antoniuk, I. Innovative System for Scheduling Manufacturing Using a Combination of Parametric Simulation Models. Sustainability 2021, 13, 9518. [CrossRef]

4. Gregor, M. Scenarios for the future technological development of humanity. ProIN-Product. Innov. 2018, 19, 44-47, (In Slovak Language).

5. Halčinová, J.; Janeková, I.; Rudy, V.; Trebuňa, P. Manufacturing structure reconfiguration based on cluster analysis of manufacturing objects. Appl. Mech. Mater. 2014, 611, 395-399. [CrossRef]

6. Zhao, Y.; Zhang, H. Application of machine learning and rule scheduling in a job-shop manufacturing control system. Int. J. Simul. Model. 2021, 20, 410-421. [CrossRef]

7. Yamada, Y.; Lei, J. Reconfiguration Process Design of a Reconfigurable Manufacturing System Using Particle Swarm Optimization. In Proceedings of the Conference on Computational Engineering in Systems Applications, Beijing, China, 4-6 October 2006.

8. Yuan, M.; Yu, H.; Huang, J.; Ji, A. Reconfigurable assembly line balancing for cloud manufacturing. J. Intell. Manuf. 2019, 30, 2391-2405. [CrossRef]

9. Trebuňa, P.; Pekarcikova, M.; Edl, M. Digital value stream mapping using the Tecnomatix plant simulation software. Int. J. Simul. Model. 2019, 18, 19-32. [CrossRef]

10. Martinkovič, M.; Mičieta, B.; Biňasová, V.; Medvecká, I.; Barbušová, M. The use of computer simulation in the company that carries out the assembly of products. In Proceedings of the TRANSCOM 2019 International Scientific Conference on Sustainable, Modern and Safe Transport, Žilina, Slovakia, 29-31 May 2019.

11. Krajcovic, M.; Gabajová, G.; Matys, M.; Grznár, P.; Dulina, L'.; Kohár, R. 3D interactive learning environment as a tool for knowledge transfer and retention. Sustainability 2021, 13, 7916. [CrossRef] 
12. Wiecek, D.; Wiecek, D.; Dulina, L. Materials requirement planning with the use of activity based costing. Manag. Syst. Prod. Eng. 2020, 28, 3-8. [CrossRef]

13. Worobel, R.; Capek, J.; Kovacova, L.; Bubenik, P.; Krajcovic, M. Improving business processes using simulation tools. MM Sci. J. 2018, 2018, 2244-2251. [CrossRef]

14. Koren, Y.; Ulsoy, A.G. Reconfigurable Manufacturing Systems; NSF Engineering Research Center for Reconfigurable Machining Systems, Report 1; The University of Michigan: Ann Arbor, MI, USA, 1997.

15. Zhu, M.; Kang, R.; He, F.; Oki, E. Implementation of Backup Resource Management Controller for Reliable Function Allocation in Kubernetes. In Proceedings of the IEEE 7th International Conference on Network Softwarization (NetSoft2021), Tokyo, Japan, 28 June-2 July 2021.

16. Zhu, M.; He, F.; Oki, E. Optimal Primary and Backup Resource Allocation with Workload-Dependent Failure Probability. In Proceedings of the International Conference on Information and Communication Technology Convergence (ICTC), Jeju, Korea, 21-23 October 2020.

17. Zajicek, J.; Kamenicky, J. Operation and maintenance of simple backup system. In Proceedings of the 16th International Scientific Conference on Electric Power Engineering (EPE), Ostrava, Czech Republic, 20-22 May 2015; VSB-Technical University of Ostrava: Ostrava, Czech Republic, 2015.

18. Levitin, G.; Xing, L. Standby Systems with Backups. In Principles of Performance and Reliability Modeling and Evaluation, 2nd ed.; Fiondella, L., Puliafito, A., Eds.; Springer Series in Reliability Engineering; Springer: Berlin/Heidelberg, Germany, 2016; pp. 373-399.

19. Zhai, Q.; Xing, L.; Peng, R.; Yang, J. Reliability analysis of cold standby systems with scheduled backups. In Proceedings of the 61st Annual Reliability \& Maintainability Symposium, Palm Harbor, FL, USA, 26-29 January 2015.

20. Yamamoto, S.; Hamaguchi, T.; Jing, S.; Koshijima, I.; Hashimoto, Y. A Hot-Backup System for Backup and Restore of ICS to Recover from Cyber-Attacks. In Advances in Human Factors, Software, and Systems Engineering, Proceedings of the AHFE 2016 International Conference on Human Factors, Software, and Systems Engineering, 27-31 July 2016; Walt Disney World: Orlando, FL, USA, 2016.

21. Qasim, L.; Hein, A.M.; Olaru, S.; Garnier, J.L.; Jankovic, M. A Model-Based Method for System Reconfiguration. J. Mech. Des. 2021, 144, 11706. [CrossRef]

22. Huang, S.H.; Wang, G.X.; Yan, Y.; Hao, J. Similarity Coefficient of RMS Part Family Grouping Considering Reconfiguration Efforts. IEEE Access 2018, 6, 71871-71883. [CrossRef]

23. Han, S.M.; Chang, T.W.; Hong, Y.S.; Park, J. Reconfiguration Decision-Making of IoT based Reconfigurable Manufacturing Systems. Appl. Sci. 2020, 10, 4807. [CrossRef]

24. Zhang, J.F.; Frey, G.; Al-Ahmari, A.; Qu, T.; Wu, N.Q.; Li, Z.W. Analysis and Control of Dynamic Reconfiguration Processes of Manufacturing Systems. IEEE Access 2018, 6, 28028-28040. [CrossRef]

25. Hashemi-Petroodi, S.E.; Dolgui, A.; Kovalev, S.; Kovalyov, M.Y.; Thevenin, S. Workforce reconfiguration strategies in manufacturing systems: A state of the art. Int. J. Prod. Res. 2021, 59, 6721-6744. [CrossRef]

26. Vavrik, V.; Gregor, M.; Grznár, P.; Mozol, Š.; Schickerle, M.; Ďurica, L.; Marschall, M.; Bielik, T. Design of Manufacturing Lines Using the Reconfigurability Principle. Mathematics 2020, 8, 1227. [CrossRef]

27. Reconfigurable Manufacturing Systems. Available online: https://ykoren.engin.umich.edu/research/rms/ (accessed on 31 January 2022).

28. Naadimuthu, G.; Gultom, P.; Lee, S.E. Fuzzy clustering in cell formation with multiple attributes. Comput. Math. Appl. 2010, 59, 3137-3147. [CrossRef]

29. Bortolini, M.; Manzini, R.; Accorsi, R.; Mora, C. An hybrid procedure for machine duplication in cellular manufacturing systems. Int. J. Adv. Manuf. Technol. 2011, 57, 1155-1173. [CrossRef]

30. Wang, T.Y.; Shaw, C.F.; Chen, Y.L. Machine selection in flexible manufacturing cell: A fuzzy multiple attribute decision-making approach. Int. J. Prod. Res. 2000, 38, 2079-2097. [CrossRef]

31. Jain, A.K.; Kasilingam, R.G.; Bhole, S.D. Cell formation in flexible manufacturing systems under resource constraints. Comput. Ind. Eng. 1990, 19, 437-441. [CrossRef]

32. VladimirVavrik/Algorithm-for-Designing-Reconfigurable-Manufacturing-Lines. Available online: https://github.com/ VladimirVavrik/Algorithm-for-designing-reconfigurable-manufacturing-lines (accessed on 31 January 2022).

33. Grznár, P.; Gregor, M.; Krajčovič, M.; Mozol, Š.; Schickerle, M.; Vavrík, V.; Ďurica, L.; Marschall, M.; Bielik, T. Modeling and Simulation of Processes in a Factory of the Future. Appl. Sci. 2020, 10, 4503. [CrossRef]

34. Deif, A.M.; ElMaraghy, W. Investigating optimal capacity scalability scheduling in a reconfigurable manufacturing system. Int. J. Adv. Manuf. Technol. 2007, 32, 557-562. [CrossRef]

35. Vodak, J.; Soviar, J.; Lendel, V. The evaluation system proposal of the businesses preparedness for cooperative management implementation. Bus. Theory Pract. 2013, 14, 315-322. [CrossRef]

36. Matuszek, J.; Seneta, T.; Plinta, D.; Wiecek, D. Manufacturability assessment in assembly processes. In Proceedings of the 21st IFAC World Congress on Automatic Control-Meeting Societal Challenges, Belin, Germany, 12-17 July 2020. 
37. Stefanik, A.; Grznar, P.; Micieta, B. Tools for continual process improvement-Simulation and benchmarking. In Proceedings of the 3rd International Conference "Business Systems Management-UPS 2004", Mostar, Bosnia and Herzegovina, 23-24 September 2004.

38. Ďurica, L.; Gregor, M.; Vavrík, V.; Marschall, M.; Grznár, P.; Mozol, Š. A Route Planner Using a Delegate Multi-Agent System for a Modular Manufacturing Line: Proof of Concept. Appl. Sci. 2019, 9, 4515. [CrossRef] 